Steiger, R., Feltrin, G., Weber, F., Nerbano, S., \& Motaval1i, M.

(2017). Experimental modal analysis of a multi-storey light-frame timber building. Bulletin of Earthquake Engineering, 15(8), 3265-3291.

https://doi .org/10.1007/s10518-015-9828-9

\title{
Experimental modal analysis of a multi-storey light-frame timber building
}

\author{
René Steiger
}

Empa

Swiss Federal Laboratories for Materials Science and Technology

Structural Engineering Research Laboratory

Ueberlandstrasse 129, CH-8600 Dübendorf, Switzerland

ph.: +4158765 4215

fax: +41587656955

rene.steiger@empa.ch

www.empa.ch

Glauco Feltrin

Empa

Swiss Federal Laboratories for Materials Science and Technology

Structural Engineering Research Laboratory

Ueberlandstrasse 129, CH-8600 Dübendorf, Switzerland

ph.: +41587654450

fax: +41587656955

glauco.feltrin@empa.ch

www.empa.ch

Felix Weber

Empa

Swiss Federal Laboratories for Materials Science and Technology

Structural Engineering Research Laboratory

Ueberlandstrasse 129, CH-8600 Dübendorf, Switzerland

ph.: +41587654536

fax: +41587656955

felix.weber@empa.ch

www.empa.ch 
Stella Nerbano

\section{Empa}

Swiss Federal Laboratories for Materials Science and Technology

Structural Engineering Research Laboratory

Ueberlandstrasse 129, CH-8600 Dübendorf, Switzerland

Masoud Motavalli

Empa

Swiss Federal Laboratories for Materials Science and Technology

Structural Engineering Research Laboratory

Ueberlandstrasse 129, CH-8600 Dübendorf, Switzerland

ph.: +41587654116

fax: +41587656955

masoud.motavalli@empa.ch

www.empa.ch 


\begin{abstract}
A 3-storey residential building with OSB-sheathed light-frame timber walls and timber-concrete composite slabs was subjected to dynamic excitation in two different stages of construction. The experiments consisted of measurements of the accelerations resulting from forced horizontal vibrations which were excited by means of a hydraulic actuator shaking a mass of $940 \mathrm{~kg}$. The exciter was positioned on the second floor of the building and rigidly anchored in the slab. It excited the building in its two main directions to vibrations with frequencies within a range of 0.2 $-14 \mathrm{~Hz}$.

Natural frequencies, modal damping ratios and mode shapes of the building were estimated using accelerations of the building measured in the four external corners of each upper floor. For increasing displacement amplitude $(1 / 8000 \mathrm{~mm} \rightarrow 0.7 \mathrm{~mm})$ the natural frequencies decreased moderately $(-15 \%)$ whereas the modal damping ratios increased markedly $(+100 \%)$. Modal damping ratios computed using ambient vibration data were generally smaller than modal damping ratios obtained from forced vibration tests, which suggests that modal damping for the levels of vibration in interest in design might be significantly underestimated if based on results from ambient vibration tests. However, the mode shapes computed using ambient vibration data turned out to be reliable. The differences in dynamic properties assessed in the different stages of construction were much smaller than expected. Compared to the natural frequencies estimated by the designer by applying a simple single degree of freedom model, the measured natural frequencies were considerably higher. This may be attributed to the impact of non-structural internal walls and walls with openings not accounted for in the designer's model.
\end{abstract}

\title{
Keywords
}

On-site testing, experimental modal analysis, ambient vibrations, forced vibrations, light-frame multi-storey timber building, horizontal stiffness 


\section{Introduction}

In Europe currently there is a strong trend to construct multi-storey residential buildings using timber as construction material. The main reasons for this trend are sustainability of wood, cost efficiency due to a high level of quality-controlled pre-fabrication, easy transportation and fast on-site erection of the building.

A big number of these buildings consist of light-frame timber (LFT) wall elements and timber-concrete composite (TCC) slabs (Kolb et al. 2008). Beside the advantages mentioned above, structures of this type provide a good performance regarding the vibration behaviour of the slabs and building physics requirements such as sound and thermal insulation.

When improving the competitiveness of light-frame timber buildings (LFTB) in the multi-storey building market segment, which is dominated by masonry and reinforced concrete building, efforts are needed in optimizing the structural concept and design with special regard to the horizontal bracing. In order to meet the requirements in serviceability and structural safety, the horizontal bracing, has to provide adequate stiffness and load-bearing capacity to the building when subjected to horizontal forces from seismic or wind action. Beside the choice and the detailing of the structural design the assumed stiffness properties of the slab and wall elements strongly impact the calculated estimates of the force distribution in the structure. Hence, with regard to the design of the bracing in order to resist seismic and wind action, it is important to know the initial stiffness of a building as well as its dynamic properties as precise as possible.

The level of seismic action to be accounted for in the design of a specific building (where type of use and site and hence, importance class and peak ground acceleration are given) mainly depends on the mass (distribution) of the building and on the first natural frequency $f_{1}$ or on the fundamental period $T_{1}$ respectively (CEN 2004c). LFTB compared to reinforced concrete or masonry buildings are expected to be less stiff. If this is true the design of the structure against seismic action could be based on much lower spectral values. 
Available dynamic experimental investigations on LFTB involve shake table tests and on-site experimental investigations of realized buildings in different stages of construction with ambient vibration tests (AVT) or forced vibration tests (FVT), the latter in most cases having been performed with low-power excitation.

Ellis and Bougard (Ellis and Bougard 2001) evaluated the stiffness of a six-storey timber framed building ( $\mathrm{B} \times \mathrm{L} \times \mathrm{H}=13 \mathrm{~m} \times 25 \mathrm{~m} \times 19.5 \mathrm{~m}$ ) by dynamic testing. The building's natural frequencies were determined at eleven stages of constructions by means of AVT. FVT was applied to identify the dynamic properties of the building in three key stages ((1) timber frame alone, (2) timber frame plus staircase, plasterboard walls and ceiling linings, (3) completed building including masonry cladding). The addition of stairways and internal plasterboard had a relatively minor effect in the torsional direction, but a considerable stiffening effect (approximately by a factor of 3.4) in the translational directions, far outweighing the increase in mass. The erection of brickwork cladding provided further significant increase in stiffness in all directions. The damping levels which had been measured were higher (damping ratio $2.4-3.9 \%$ ) than those likely to be encountered in typical concrete and steel constructions (1.6\% and $0.8 \%$ ) respectively (CEN 2004b). The authors attributed this finding to the many flexible joints within the timber building which provide energy dissipation mechanisms.

Shake table tests (Filiatrault et al. 2008; Filiatrault et al. 2010) on a full-scale twostorey light-frame wooden townhouse ( $\mathrm{B} \times \mathrm{L}$ x H $=7 \mathrm{~m}$ x $18 \mathrm{~m}$ x $5.3 \mathrm{~m}$ ) designed according to the U.S. Engineered Seismic Requirements aimed at determining the dynamic characteristics and the seismic performance of the test building under different excitation intensities. Before and after each seismic test, the dynamic properties were estimated from the results of AVT where the building was excited by a low-level white-noise acceleration input with a flat spectrum $(0.5-50 \mathrm{~Hz})$ frequency band and a root mean square (RMS) amplitude $<0.1 g$. The experiments revealed a marked impact of additionally installed interior gypsum wallboard finishes and exterior stucco finishes on the LFT walls. The natural frequencies along the transverse and longitudinal directions of the test building were increased by 9 and 5\% respectively after installation of the interior gypsum 
cladding. When also the stucco was applied to the façade of the LFT wall elements, the increase in natural frequencies amounted to additional $3 \%$ in transvers and 9\% in longitudinal direction (Filiatrault et al. 2010).

Van de Lindt et al. (van de Lindt et al. 2010) report about shake table tests on a full-scale six-storey LFTB (B x L x H $\approx 12 \mathrm{~m}$ x $18 \mathrm{~m}$ x $17 \mathrm{~m}$ ), the aims of which were to demonstrate that a developed performance based design method worked on this building and to gain a better understanding of how midrise LFTB respond, in general, to a major earthquake. In the course of the test program the natural periods of the building before and after each seismic test were derived from experiments with white noise excitation input. There was a shift in natural frequencies $(-15 \%)$ as the building was slightly damaged.

Sartori et al. (Sartori et al. 2012) performed shake table tests on a LFTB with three storeys ( $\mathrm{B} \times \mathrm{L} \times \mathrm{H} \approx 5 \mathrm{~m} \times 7 \mathrm{~m} \times 7.5 \mathrm{~m}$ ). The goal of the research project was to evaluate the seismic behavior of a typical Italian prefabricated timber building and to study the interaction between the structural components. Before and after each seismic test natural frequencies, mode shapes and modal damping ratios were determined by exciting the building with a low amplitude white noise. In seismic tests with peak acceleration smaller than $0.7 g$ the fundamental natural frequency was found unchanged. After the $0.7 g$-test the natural frequency decreased by $1 \%$ and after an additional seismic test with $1.0 \mathrm{~g}$ the decrease in natural frequency was again $4 \%$. However, no significant mode shape variation (mode 1) occurred.

By means of AVT on a LFTB (B x L x H = $16.5 \mathrm{~m}$ x $44.6 \mathrm{~m}$ x $14.2 \mathrm{~m}$ ) Hafeez et al. (Hafeez et al. 2014) wanted to compare experimentally derived natural frequencies with predictions when applying the National Building Code of Canada. The tests were carried out at a construction stage when all structural framing and sheathing elements were installed but no wall finishing materials (gypsum wall boards, etc.) were present. In agreement with Rainieri et al. (Rainieri et al. 2010) the authors found that under normal operating conditions of the structure AVTs yield good estimates of the natural frequencies and mode shapes but unreliable estimates of modal damping ratios. In addition the authors 
report about studies (by e.g. (Ellis and Bougard 2001; Kharrazi et al. 2002; Kohara and Miyazawa 1998; Ohashi et al. 1998; Sato et al. 2000)) where the dynamic characteristics obtained from AVT were compared with those from FVT. Lower natural frequencies were found with FVT compared to AVT, which is to be attributed to the amplitudes in FVT being markedly larger than at ambient level.

In the course of further development of the post-tensioned timber frame concept "Pres-Lam" shake table tests were carried out on a 3D 3-storey post-tensioned test specimen that had been designed to withstand high levels of seismic loading without damage (Ponzo et al. 2012). The natural frequencies of the structure were assessed with two different excitation sources: hammer impact excitations and sine-sweep shake table motions. The specimen consisted of a single bay in both directions and was produced in $2 / 3^{\text {rd }}$ scale with an inter-storey height of $2 \mathrm{~m}$ and a frame footprint of $4 \mathrm{~m}$ by $3 \mathrm{~m}$. It was subjected to dynamic tests with different levels of peak ground acceleration (PGA) up to a maximum of $0.77 \mathrm{~g}$ with and $0.58 \mathrm{~g}$ without dissipative steel angle reinforcing of the joints (Smith et al. 2014). At comparable levels of PGA the addition of the steel reinforcing reduced drifts by $32 \%$ without increases in peak floor accelerations.

In the framework of the extensive Swiss National Research Program NRP 66 "Resource Wood" the unique opportunity arose to experimentally investigate the dynamic properties of a 3-storey LFTB in Switzerland (Fig. 1) by means of largescale on-site experiments. Prevention of damage in the course of the experimental campaign was an important pre-requisite to be reached.

The tests aimed at identifying natural frequencies and mode shapes as well as the modal damping ratio of the building in its two main directions for horizontal excitation of different amplitudes. In order to identify the impact of non-structural components on the dynamic properties of the building the experiments were carried out in two different stages of construction. The tests were planned in close collaboration with the engineering office Pirmin Jung Ingenieure für Holzbau AG, which was responsible for the design of the building. 


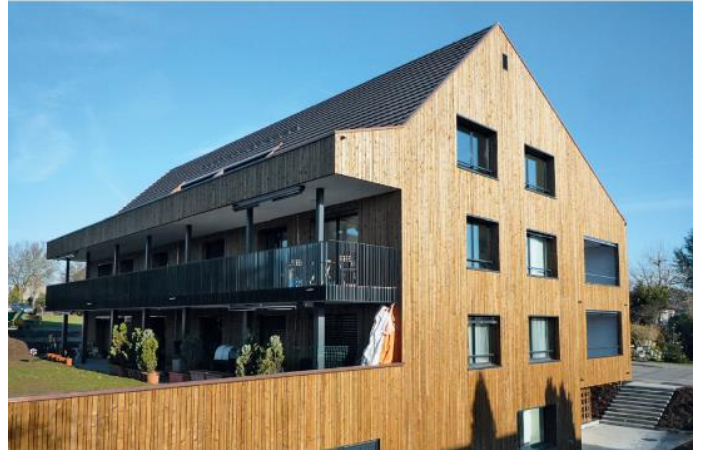

(a)

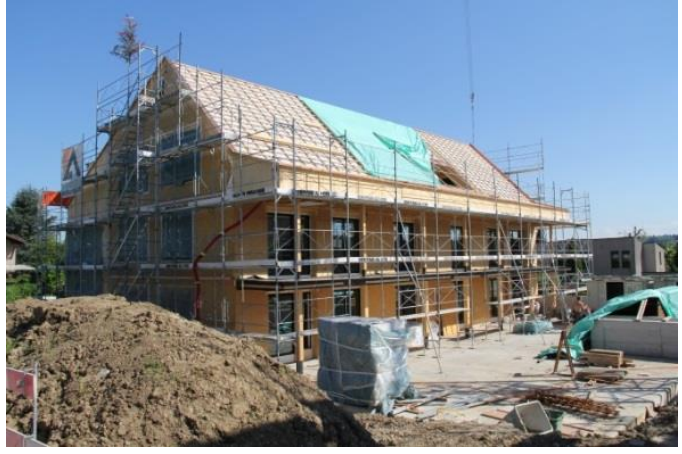

(b)

Fig. 1 Investigated residential LFTB after completion of construction work (a) and in construction stage 2 during on-site testing (b)

\section{Construction and design of the investigated building}

The investigated residential building (importance class I according to (CEN 2004c)) is $24 \mathrm{~m}$ in length and $14.6 \mathrm{~m}$ in width (Fig. 2). The total height of the light-frame timber structure above the subterranean garage amounts to $11.5 \mathrm{~m}$. The heights of ground floor and storey 1 are $h_{0}=h_{1}=2.80 \mathrm{~m}$. Storeys 2 and 3 (attic) have heights of $h_{2}=3.00 \mathrm{~m}, h_{3}=2.40 \mathrm{~m}$ respectively.

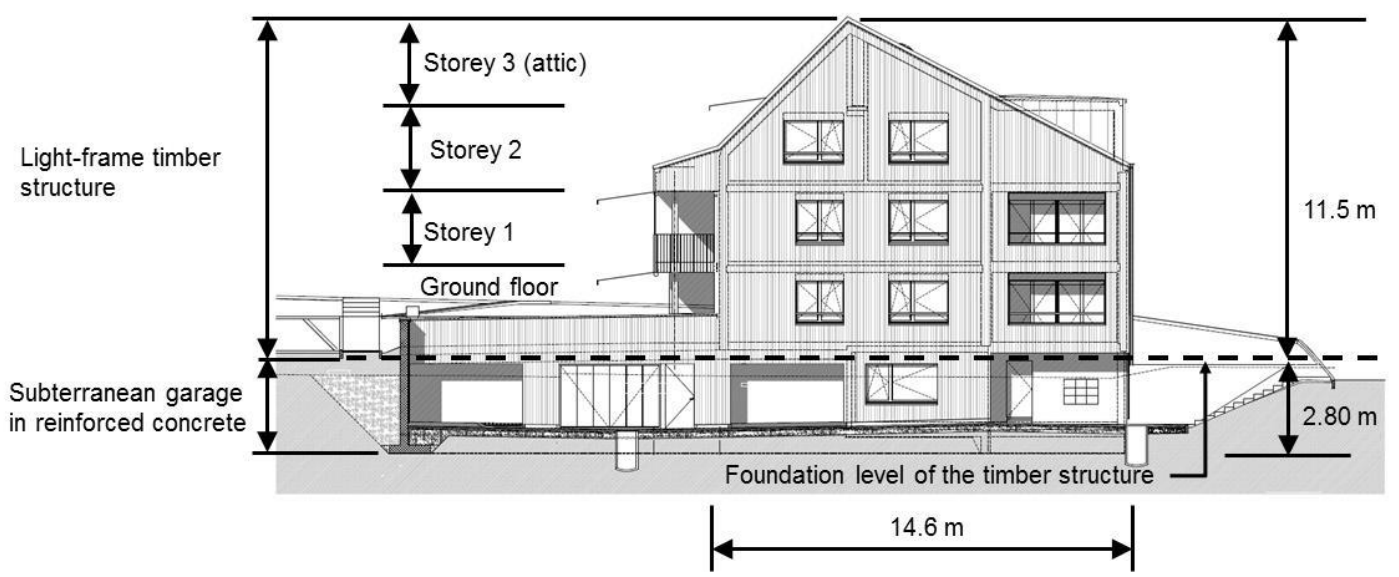

(a) 


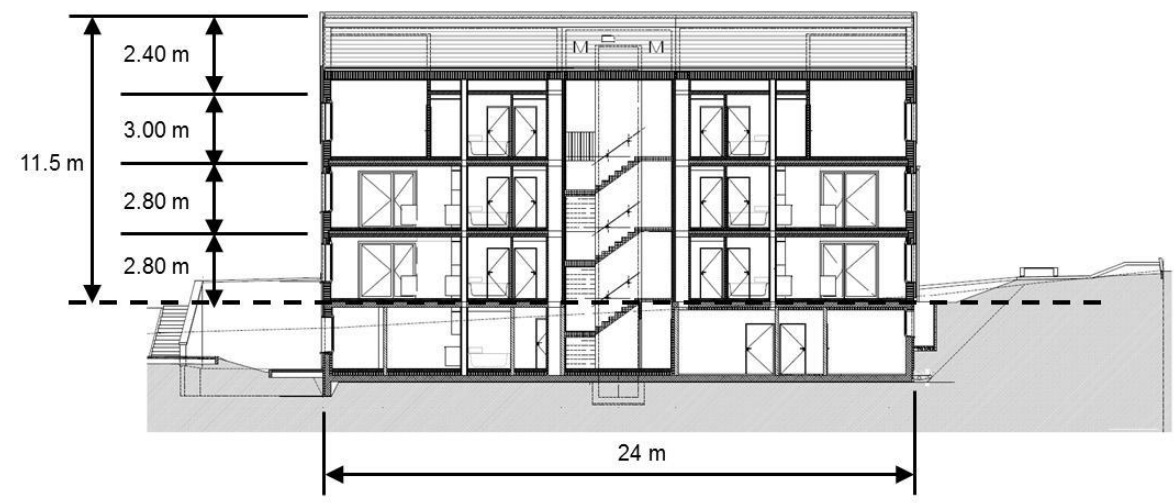

(b)

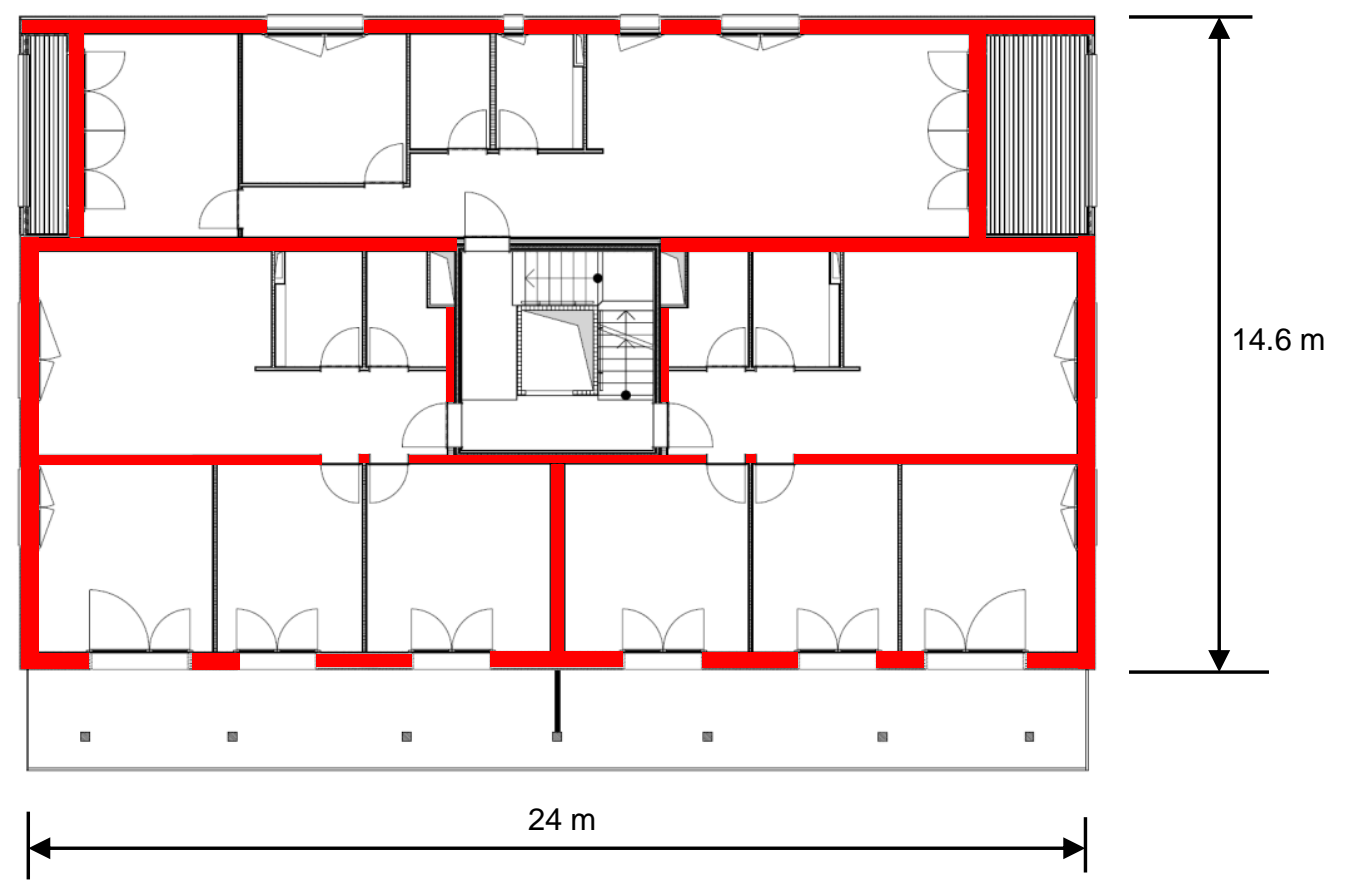

(c)

Fig. 2 Short side view (a), long side view (b) and plan view (c) of the investigated LFTB. In Fig. 2 (c) the structural walls are marked with red colour.

The building was designed according to the Swiss codes SIA 260 (Basis of structural design) (SIA 2003a), SIA 261 (Actions on structures) (SIA 2003b) and SIA 265 (Timber structures) (Schweizerischer Ingenieur- und Architektenverein sia 2003) / SIA 265/1 (Timber structures - Supplementary specifications) (SIA 2003c; SIA 2009). The design for wind loads was based on characteristic values of wind force of $q_{k}=1.07 \mathrm{kN} / \mathrm{m}^{2}$ on the short side of the building and $q_{k}=0.68 \mathrm{kN} / \mathrm{m}^{2}$ on the long side respectively, representing a reference value of dynamic wind pressure of $q_{p, 0}=0.9 \mathrm{kN} / \mathrm{m}^{2}$. 
The building is located in Oberglatt, near Zurich, within the seismic zone Z 1 according to the Swiss code SIA 261 (SIA 2003b). In zone Z 1 the design value of the horizontal ground acceleration for a return period of 475 years is $a_{g d}=0.6 \mathrm{~m} / \mathrm{s}^{2}(6 \% g)$. Fig. 3 shows elastic response spectra for a damping ratio of $\xi=0.05$ given in the Swiss code SIA 261 (SIA 2003b).

The building is founded on deposits of extensive cemented gravel and sand (i.e. soil class B, Fig. 3). Applying a Single Degree of Freedom (SDOF) model, the designer estimated the first natural frequencies $T_{1, y} \approx 1 \mathrm{~s}$ (corresponding to a natural frequency of $f_{1, y} \approx 1 \mathrm{~Hz}$ ) in the transversal direction of the building and $T_{1, x} \approx 0.85$ s (i.e. $f_{1, x} \approx 1.18 \mathrm{~Hz}$ ) in the longitudinal direction respectively. Both natural periods are located in the descending branches of the seismic response spectra in Fig. 3, which would allow a seismic design with much lower design accelerations compared to the plateau values. Design of the building for seismic hazards was made with the force based method assuming a behaviour factor of $q=3$ and a damping ratio of $\xi=0.05$. 


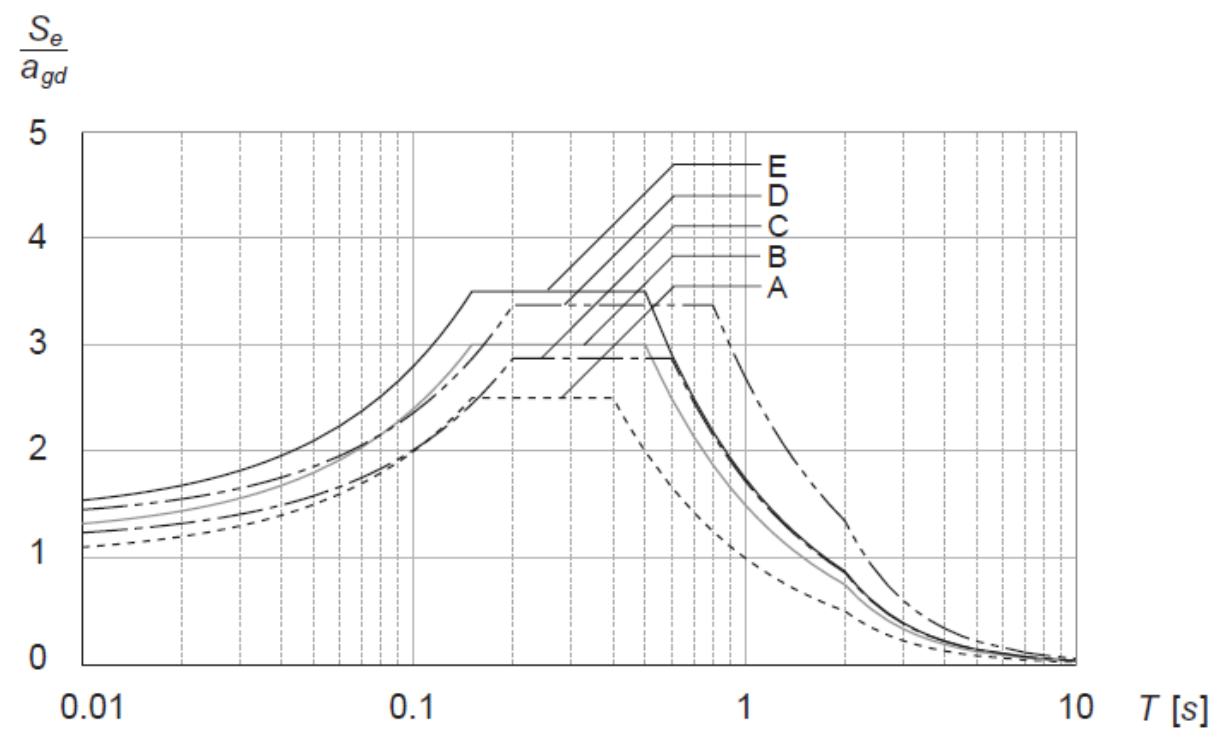

\begin{tabular}{|l|l|}
\hline Ground type & Description \\
\hline A & Firm rock \\
\hline B & $\begin{array}{l}\text { Deposits of extensive cemented gravel and sand and/or over- } \\
\text { consolidated soils with a thickness exceeding } 30 \mathrm{~m}\end{array}$ \\
\hline C & $\begin{array}{l}\text { Deposits of normally consolidated and uncemented gravel and sand } \\
\text { and/or moraine with a thickness exceeding } 30 \mathrm{~m}\end{array}$ \\
\hline D & $\begin{array}{l}\text { Deposits of unconsolidated fine sand, silt and clay with a thickness } \\
\text { exceeding } 30 \mathrm{~m}\end{array}$ \\
\hline E & $\begin{array}{l}\text { Alluvial surface layer of ground classes C or D with a thickness of } 5 \text { to } \\
30 \text { m lying above a stiffer layer of the ground classes A or B }\end{array}$ \\
\hline
\end{tabular}

Fig. 3 Elastic response spectra for a damping ratio of 0.05 according to the Swiss code SIA 261 (SIA 2003b) for ground types A - E.

Above the subterranean garage the building is supported by a timber structure consisting of LFT walls, TCC slabs in storeys 1 and 2 and a dowelled-laminated timber (DLT) slab "Brettstapel" (Fig. 4a) in storey 3. On top of the building there is a rafter roof covered with clay tiles (Fig. 4b). The TCC slabs (12 cm DLT elements of strength grade C24 (CEN 2009a) in combination with $12 \mathrm{~cm}$ reinforced class C25/30 concrete (Fig. 4c)) transfer the vertical and horizontal forces to the LFT walls which in the first storey are anchored to the reinforced concrete (RC) top cover of the subterranean garage by strong anchors of types Hilti HDA M16 and HAS-TZ M16 (www.hilti.com).

Façade walls carrying only vertical forces are made from LFT elements on the outer side sheathed with hardboards (Akers 1966; CEN 2001; CEN 2004a) and on the inside with $15 \mathrm{~mm}$ tick oriented strand board (OSB) panels of grade 3, i.e. 
panels for load-bearing use in humid conditions (CEN 2001; CEN 2004d; CEN 2006). The LFT elements of façade wall parts which contribute to bracing the building are sheathed with $15 \mathrm{~mm}$ OSB-3 panels on both sides of the timber frame (Fig. 4d). Inner walls separating flats or rooms within flats as well are of type LFT, however, sheathed with gypsum fibre board panels (CEN 2009c) and gypsum plasterboard panels (CEN 2009b) on both sides of the frame (Fig. 4e, f).

All frames (rails and studs) of the LFT wall elements are made of C24 grade (CEN 2009a) Norway spruce (Picea abies Karst.) timber. The OSB-, hardboardand gypsum fibre board- / plaster board-panels are connected to the timber frames by means of 2 to 3 rows of staples with a tensile strength of $f_{u} \geq 800 \mathrm{~N} / \mathrm{mm}^{2}$, diameter $1.53 \mathrm{~mm}$, length $50 \mathrm{~mm}$ and inter-connector distances of $25 \mathrm{~mm}$.

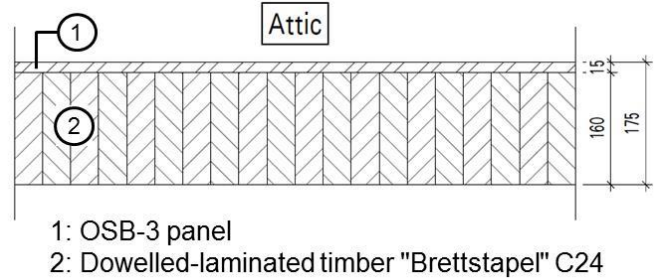

(a)

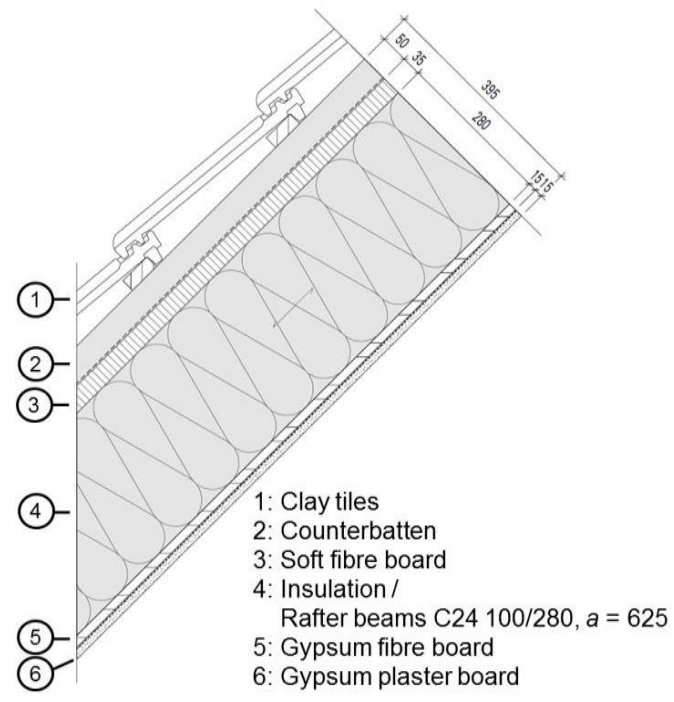

(c)

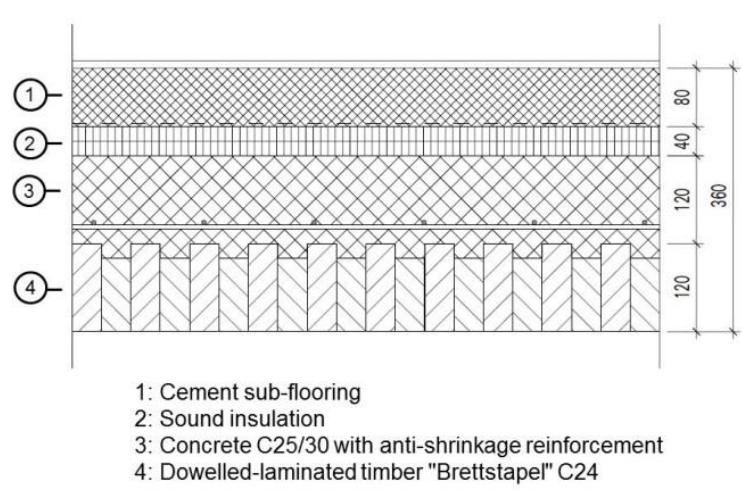

(b)

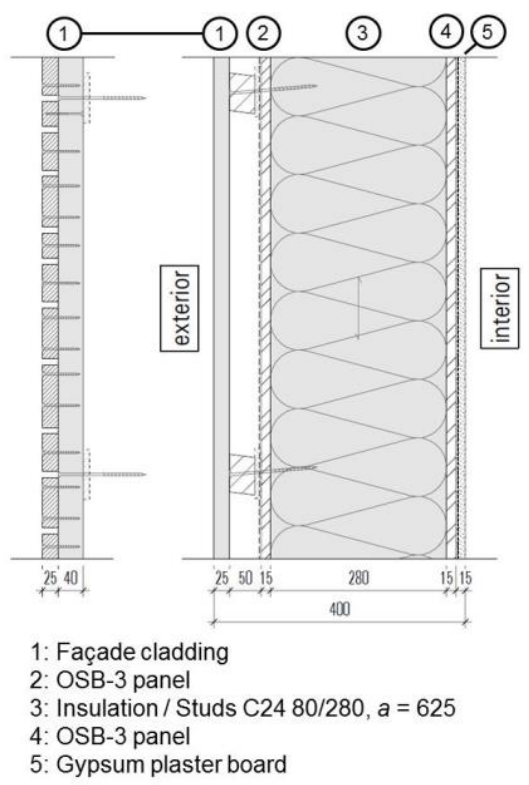

(d) 


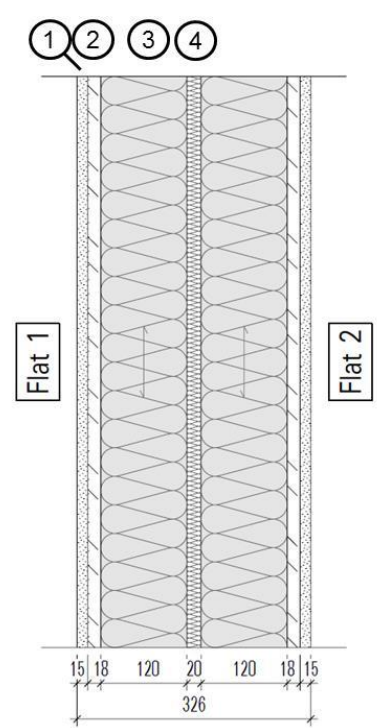

1: Gypsum plaster board

2: Gypsum fibre board

3: Insulation 1 / Studs C24 60-120/120, $a=625$

4: Insulation 2

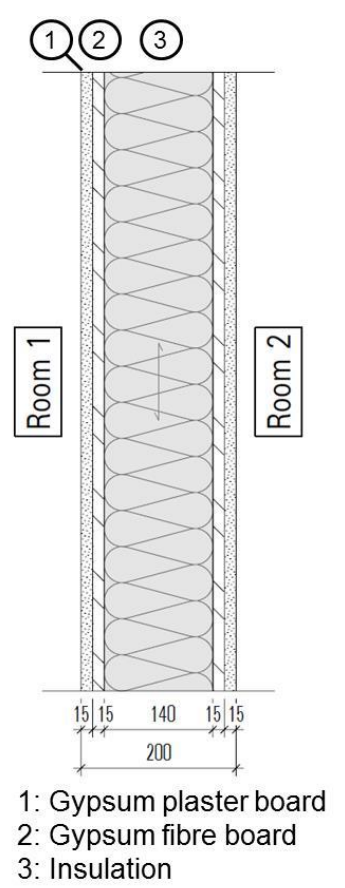

(f)

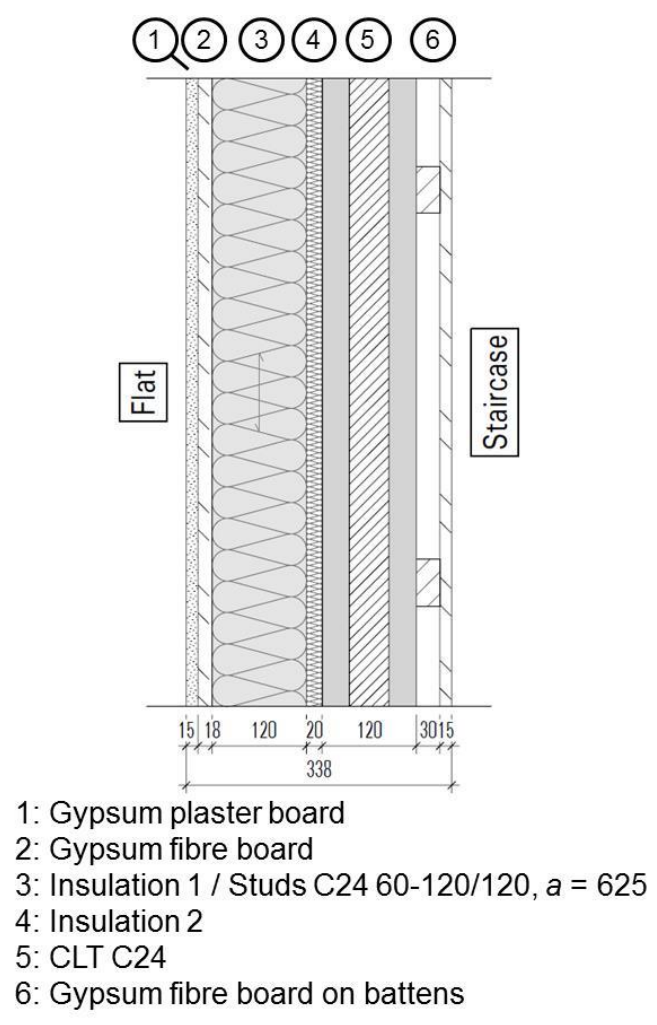

$(\mathrm{g})$

Fig. 4 Construction details of the most important elements of the LFTB: DLT slab in storey 3 (a), TCC slab in storeys 1 and 2 (b), rafter roof covered with clay tiles (c), LFT façade walls (d), internal walls separating flats from neighbour flats (e), rooms within flats (f) and flats from the staircase (f). All dimensions in mm. 
In order to prevent noise impact from the staircase and the elevator shaft to the flats, staircases are supported by an isolated cross-laminated (CLT) timber structure decoupled from the main load-bearing LFT structure of the building (Fig. 4g). Vertically stacked pre-fabricated RC elements founded directly on the top cover of the subterranean garage form the elevator shaft. Hence, also the elevator shaft is not directly connected to the main load-bearing structure of the building.

\section{Experiments}

\subsection{Method}

First AVT were carried out in order to estimate the natural frequencies of the building. FVT were then performed by exciting the building with a hydraulic exciter in its two main horizontal directions, however, limiting the excitation to levels where no damages could occur. A more detailed description of the experiments carried out will be given in 3.4.

Two main stages of construction were investigated. In these two stages the key structural elements contributing to the mass and the horizontal stiffness of the building were in stages as described in Table 1. 
Table 1 Investigated stages of construction.

\begin{tabular}{|c|c|c|}
\hline Element & Stage 1 & Stage 2 \\
\hline $\begin{array}{l}\text { Roof } \\
\text { (Fig. 4c) }\end{array}$ & \multicolumn{2}{|c|}{ No clay tiles on the roof yet } \\
\hline \multirow{3}{*}{$\begin{array}{l}\text { TCC slabs } \\
\text { (Fig. 4b) }\end{array}$} & \multicolumn{2}{|c|}{ No sub-flooring installed } \\
\hline & \multicolumn{2}{|c|}{ Shear connections between slab and wall elements installed } \\
\hline & Fully supported by telescopic studs & Supported underneath the exciter \\
\hline \multirow{7}{*}{$\begin{array}{l}\text { Façade LFTSW } \\
\text { (Fig. 4d) }\end{array}$} & \multicolumn{2}{|c|}{ Façade cladding not yet installed } \\
\hline & $\begin{array}{l}\text { Interior gypsum plaster boards not } \\
\text { mounted yet }\end{array}$ & $\begin{array}{l}50 \% \text { of interior gypsum plaster } \\
\text { boards mounted }\end{array}$ \\
\hline & $\begin{array}{l}\text { Stapled, space between connectors: } \\
500 \mathrm{~mm}^{1)} \text { or } 25 \mathrm{~mm}^{2)} \text { respectively }\end{array}$ & $\begin{array}{l}\text { Stapled, space between connectors: } \\
\qquad 25 \mathrm{~mm}\end{array}$ \\
\hline & No window and door frames & Window and door frames mounted \\
\hline & No windows & Windows mounted, closed \\
\hline & No French windows & French windows mounted, closed \\
\hline & $\begin{array}{l}\text { Hold downs in storey } 1 \text { not mounted } \\
\text { yet }\end{array}$ & Hold downs in storey 1 mounted \\
\hline \multirow{4}{*}{$\begin{array}{l}\text { Internal LFTSW } \\
\text { (Fig. } 4 \mathrm{e}, \mathrm{f})\end{array}$} & \multicolumn{2}{|c|}{ Stapled, space between connectors: $25 \mathrm{~mm}$} \\
\hline & $\begin{array}{l}\text { Gypsum plaster boards not mounted } \\
\text { yet }\end{array}$ & $\begin{array}{l}50 \% \text { of the gypsum plaster boards } \\
\text { mounted }\end{array}$ \\
\hline & No door frames & Door frames mounted \\
\hline & $\begin{array}{l}\text { Hold downs in storey } 1 \text { not mounted } \\
\text { yet }\end{array}$ & Hold downs in storey 1 mounted \\
\hline \multicolumn{3}{|c|}{ Façade walls assigned to carry only vertical forces } \\
\hline \multicolumn{3}{|c|}{ Façade walls assigned to carry vertical and horizontal forces } \\
\hline
\end{tabular}

\subsection{Excitation in forced vibration tests}

The exciter adopted for the tests (Fig. 5) consists of a hydraulic actuator of type Instron ${ }^{\circledR}$ which drives a mass of $940 \mathrm{~kg}$ guided by a horizontal slide bearing system. Actuator and shaking mass are mounted on a stiff steel rack with main dimensions $2465 \mathrm{~mm} \times 800 \mathrm{~mm}$. The rack is to be bolted to the investigated structure in order to transfer the force. The total mass of the steel rack with hydraulic actuator and shaking mass is $1765 \mathrm{~kg}$. The maximum displacement range of the shaking mass is $+/-125 \mathrm{~mm}$ and the shaking force is constrained by the maximum dynamic actuator force of $+/-32 \mathrm{kN}$. 


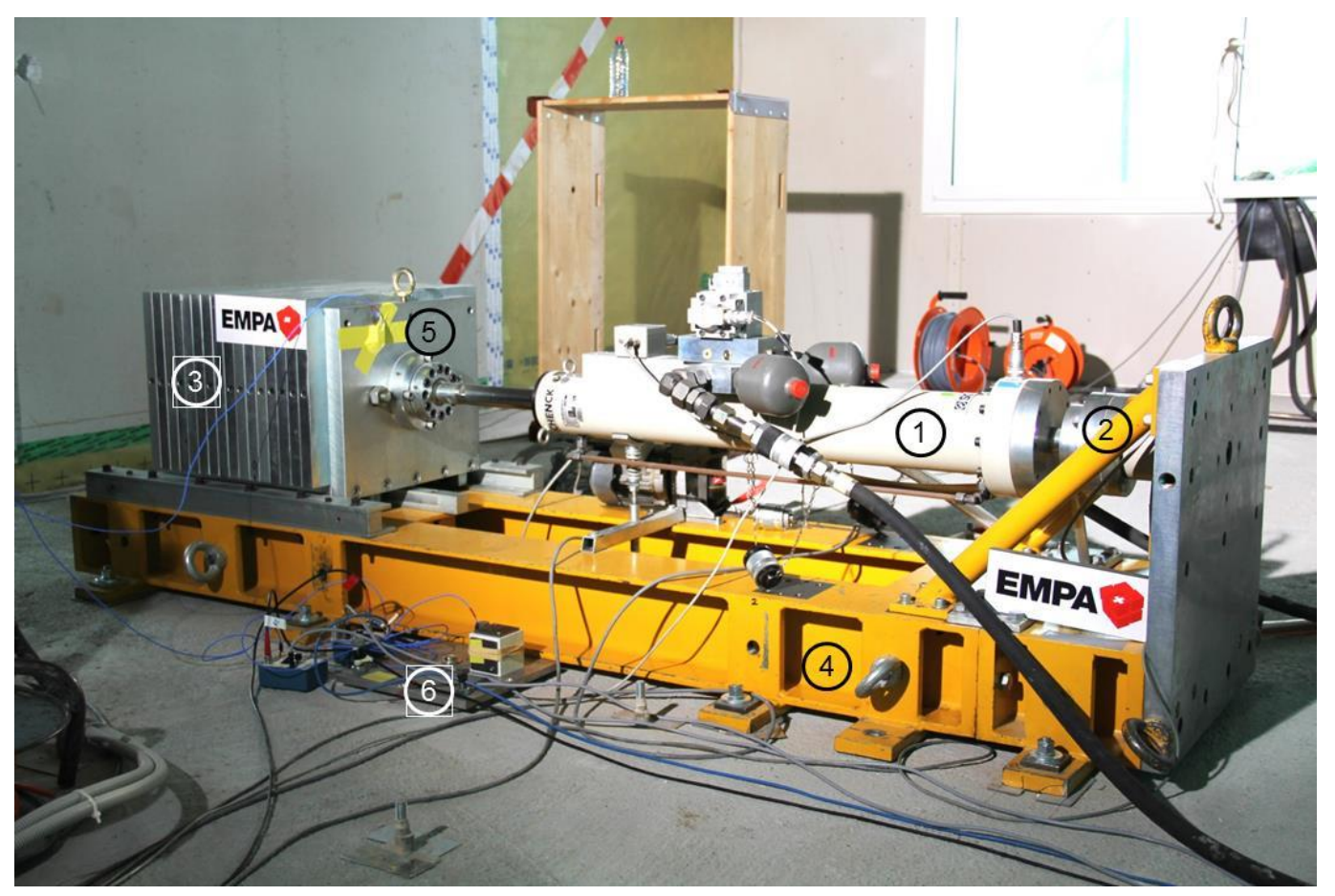

Fig. 5 Horizontal exciter rigidly anchored to the storey 2 TCC slab with: Hydraulic Instron ® actuator (1) with load cell Schenck PM40 (2) and $940 \mathrm{~kg}$ shaking mass (3) mounted to a steel rack (4). The acceleration of the shaking mass and of the slab next to the exciter were recorded by means of uniaxial accelerometers of type PCB 3701G3FA3G $(5,6)$.

In order to be able to transfer as much excitation power as possible to the building the exciter was positioned in the $2^{\text {nd }}$ storey (Fig. 6a), hereby accounting also for the fact that the lucarne balcony in the $2^{\text {nd }}$ storey offered the only possibility to lift the exciter into the building and out of it after completion of the experiments. The exciter was placed in a room big enough for changing the orientation of the exciter by $90^{\circ}$ in order to excite the building in its two main directions. Fig. $6 \mathrm{~b}$ shows the position of the exciter $E$ together with centres of mass $M$ and stiffness $S$ as well as the directions of excitation. Calculation of mass centre and stiffness centre of the building according to the procedure described in (Brunner et al. 2010) revealed that both $M$ and $S$ are located in the centre of the elevator shaft close to each other. 


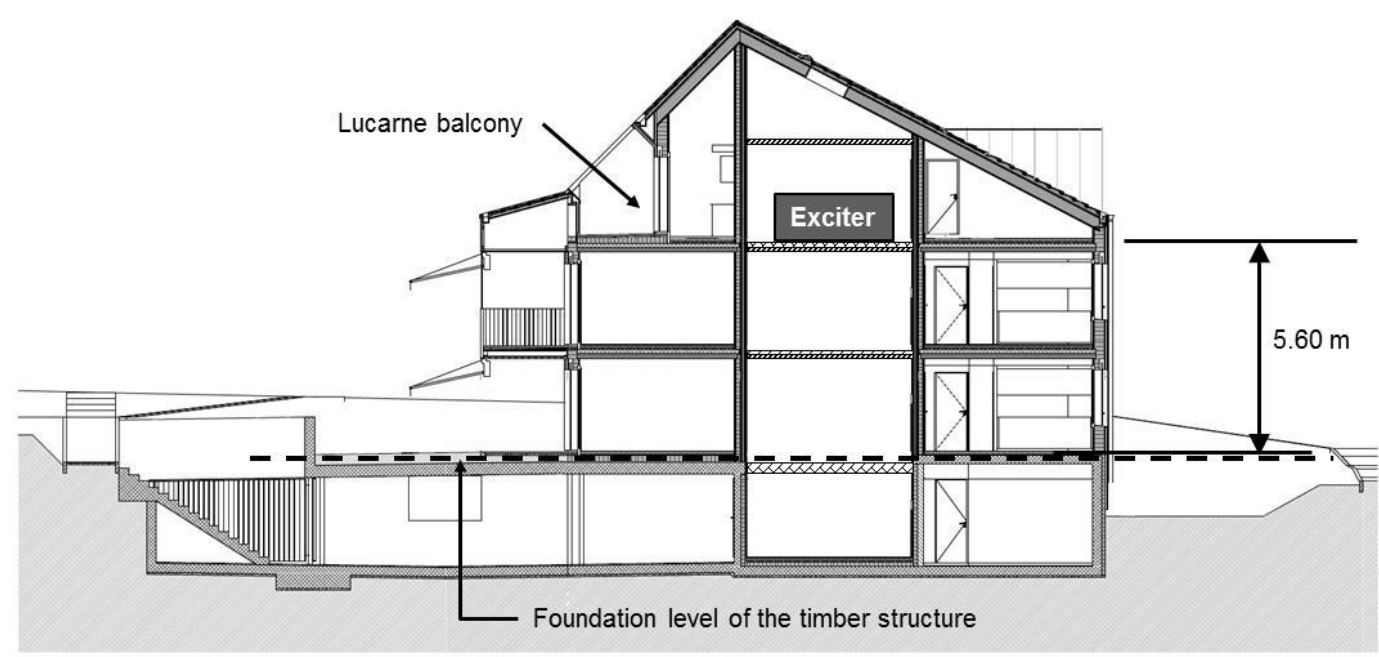

(a)

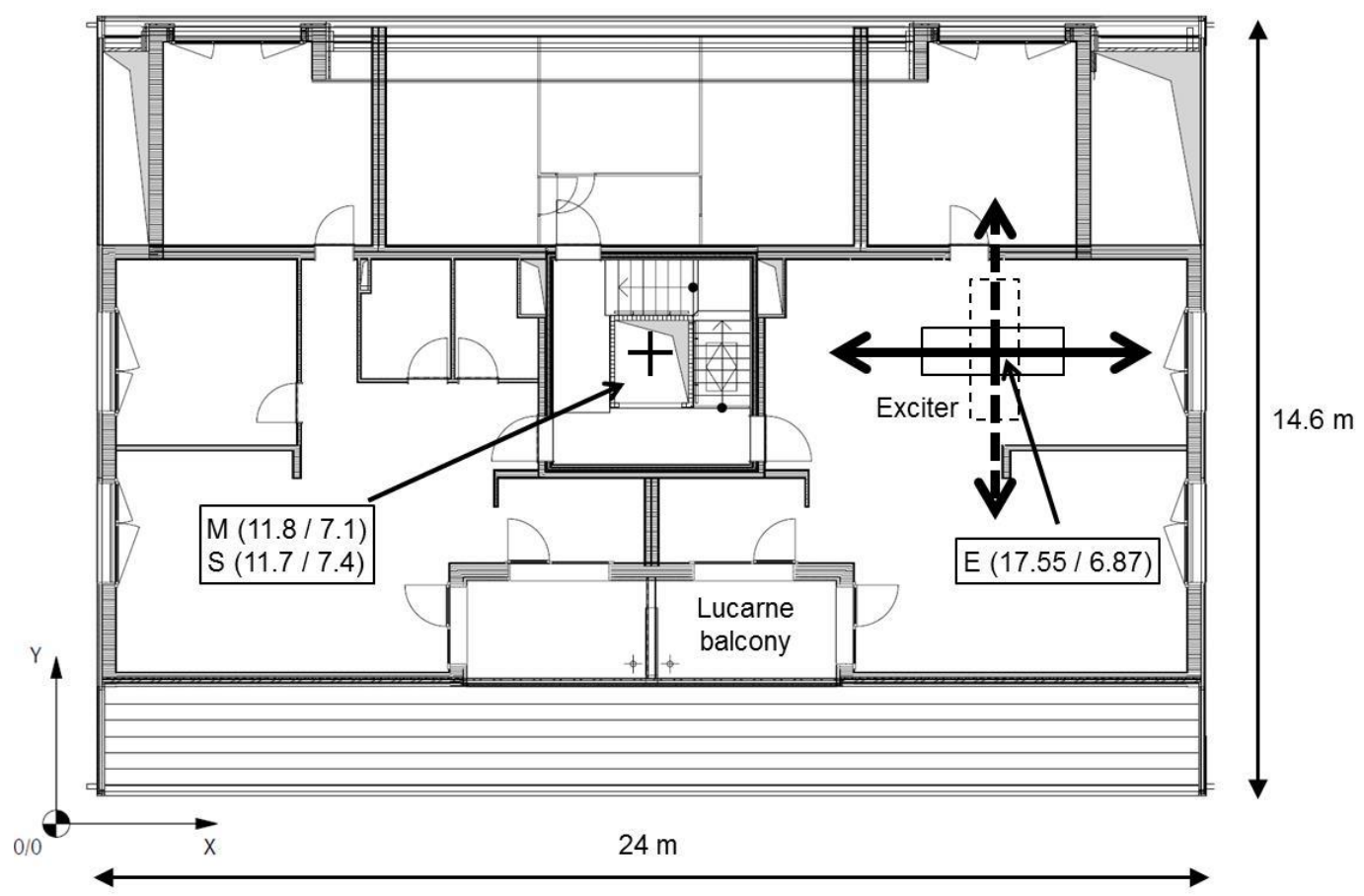

(b)

Fig. 6 Lifting the exciter into the $2^{\text {nd }}$ storey of the building via a lucarne balcony (a) and final position of the exciter $E$ with respect to centres of mass $M$ and stiffness $S$ (b). The building was excited to vibrate in its two main directions.

The exciter was rigidly anchored to the TCC slab by means of a Hilti dynamic anchoring set consisting of eight grade 8.8 carbon steel anchor rods HIT-V with metric thread M16 mounted with injectable mortar HIT-HY 200-A. In order to transfer the excitation forces to the slab without causing damage the slab had to be reinforced locally by additional crosswise oriented rebars and the vertical mass of 
the exciter had to be carried by a series of telescopic metal studs in all storeys underneath the exciter.

\subsection{Placement of sensors}

Good quality identification of modal parameters and in particular mode shapes requires a correct location of the sensors. It is good practise to exploit modal analysis results obtained by numerical models of the structure as a guide for sensor placement. For the timber building under investigation, the problem of sensor placement is less critical. Since the floors are very rigid in in-plane direction (diaphragm), their horizontal motion corresponds to the motion of a rigid body. Such a motion can be decomposed into two perpendicular translational and a rotational motion. In this case, a good choice is always to place the sensors at the corners of the floor if the centre of rotational motion is not too far away from the centre of gravity of the floor, which is a requirement that was satisfied by the building. Only the upper floors were instrumented but not the reinforced concrete floor of the basement because the large mass and high rigidity of the basement as well as its embedding in the ground produced motions that were order of magnitude smaller than the motion of the floors.

The positions of the sensor locations are displayed in Fig. 7. In each location the horizontal vibrations were measured in two orthogonal directions ( $\mathrm{x}$ or strong building axis and y or weak building axis). The locations P1 to P8 were instrumented with uniaxial acceleration sensors of the type PCB 393B31 (Fig. 8a). These sensors have an operation bandwidth of 0.1 to $200 \mathrm{~Hz}$, an amplitude range of $\pm 5 \mathrm{~ms}^{-2}$ and a resolution of $10 \mu \mathrm{ms}^{-2} \mathrm{RMS}$. The sensor locations P9 to P12 were instrumented with slightly less sensitive uniaxial acceleration sensors PCB 393A03 (Fig. 8b), which have an operation band-width of 0.5 to $6000 \mathrm{~Hz}$, a maximum amplitude of $\pm 49 \mathrm{~ms}^{-2}$ and a resolution of about $100 \mu \mathrm{ms}^{-2} \mathrm{RMS}$. 


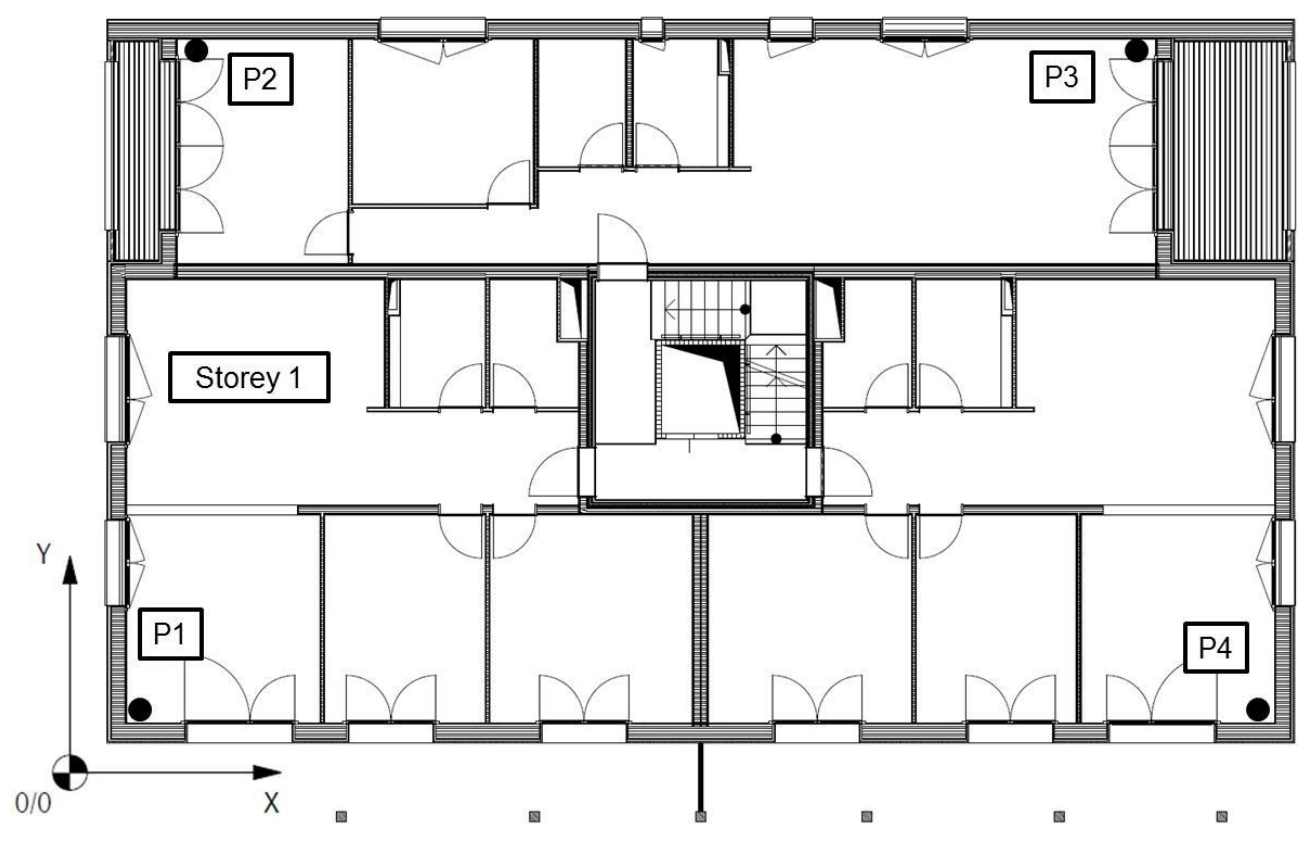

(a)

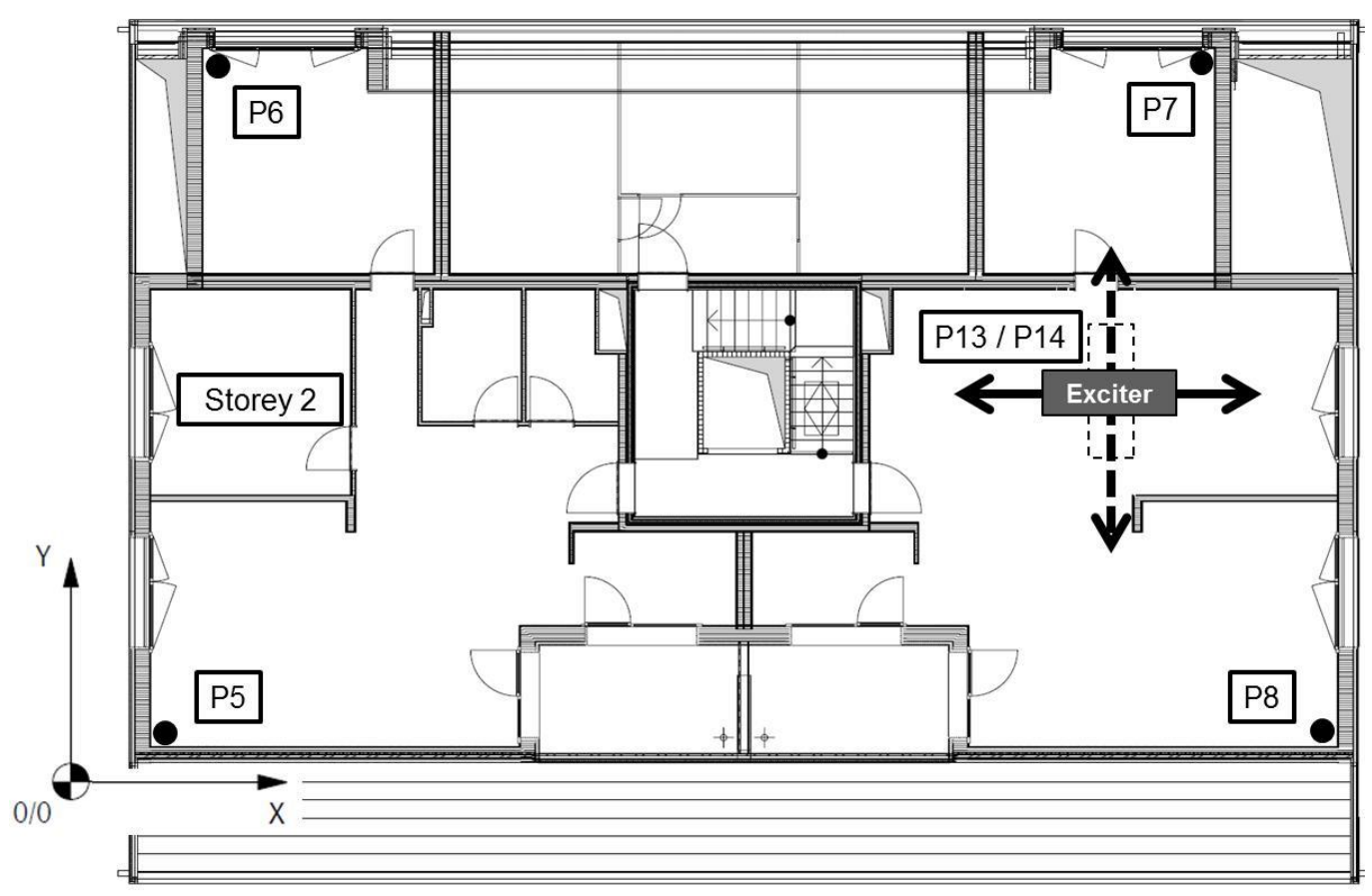

(b) 


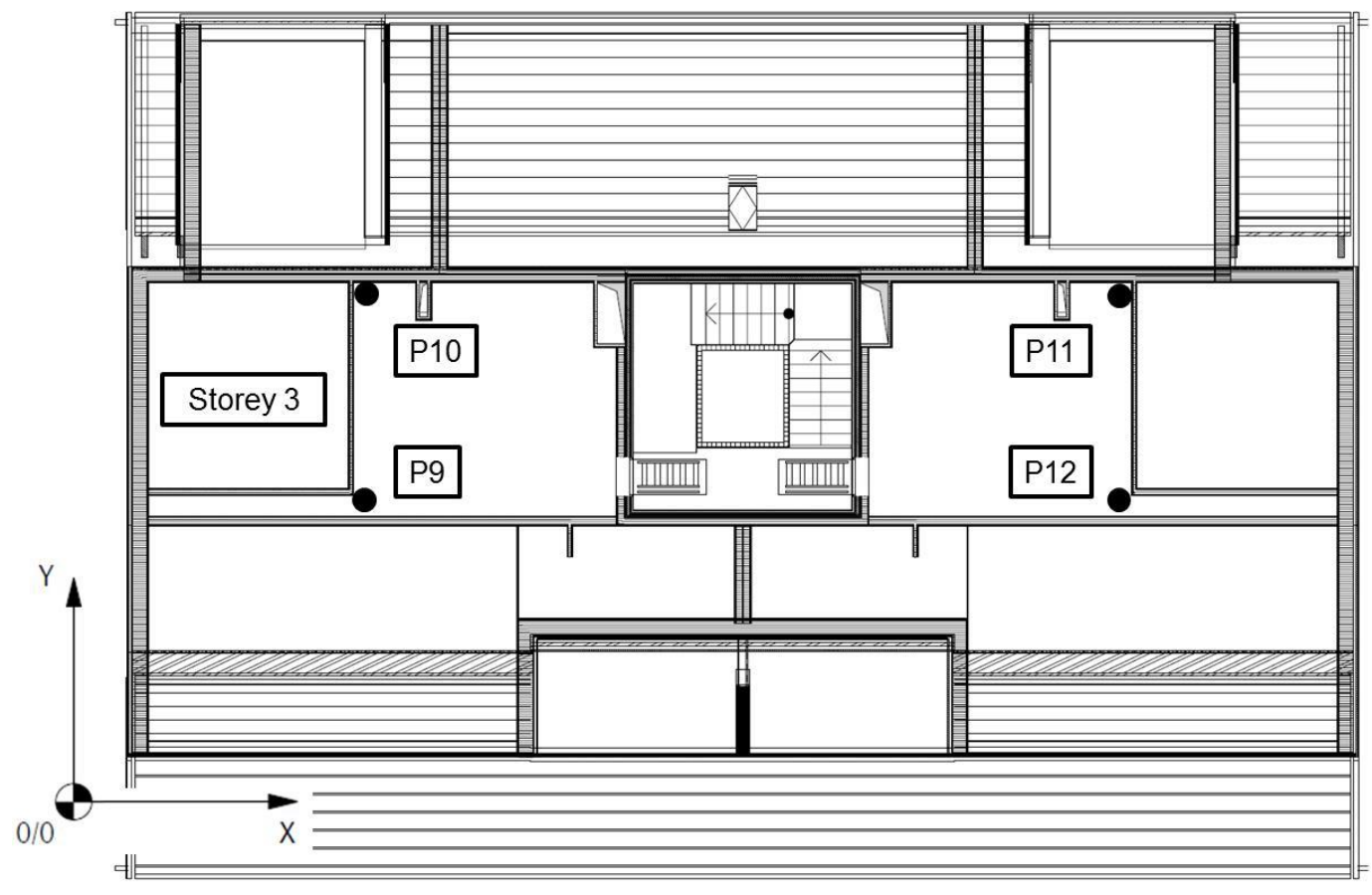

(c)

Fig. 7 Positions of the sensor locations in storey 1 (a), 2 (b) and 3 (c). In each position two sensors were placed, measuring the acceleration in $\mathrm{x}$ - and $\mathrm{y}$-direction. At positions $\mathrm{P} 1$ to P8 uniaxial acceleration sensors of type PCB 393B31 (Fig. 8a) were used. Sensor locations P9 to P12 were instrumented with uniaxial acceleration sensors of type PCB 393A03 (Fig. 8b).

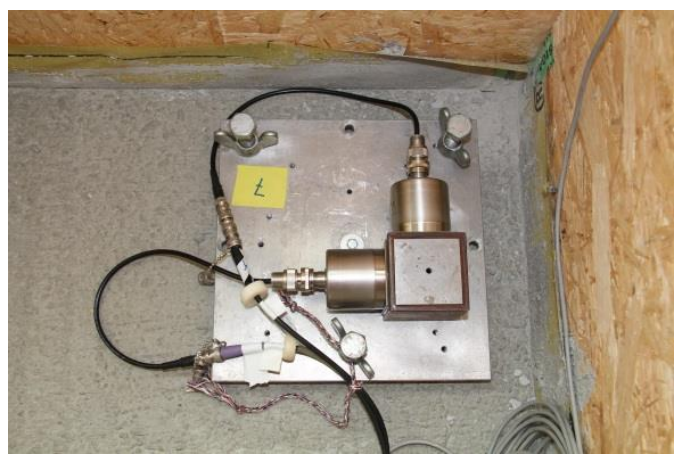

(a)

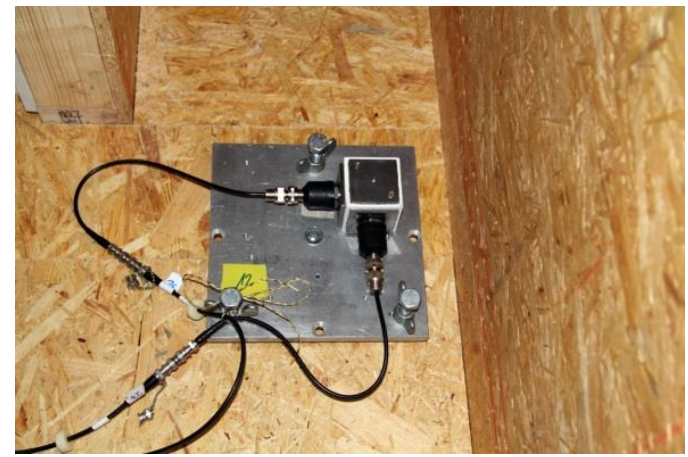

(b)

Fig. 8 Sensor position 7 with acceleration sensor PCB 393B31 (a) and sensor position 12 with acceleration sensor PCB 393A03 (b)

In addition to sensor locations for detecting the vibration modes (P1 to P12) the motion of the floor in the direction of the excitation force in the immediate vicinity of the vibration exciter mass P13 (6) in Fig. 5) and the motion of the exciter mass P14 (5) in Fig. 5) were recorded. Uniaxial accelerometers of type PCB 3701G3FA3G were used for sensing these motions. These sensors have an operation bandwidth of 0 to $100 \mathrm{~Hz}$, an amplitude range of $\pm 30 \mathrm{~ms}^{-2}$ and a 
resolution of $300 \mu \mathrm{ms}^{-2} \mathrm{rms}$. To electrically insulate the sensors, each sensor (except the one placed on the exciter mass) was mounted with a screw on a wooden cube which was attached to an aluminium plate (Fig. 8). Each plate was aligned horizontally and eventually fixed to the floor with a screw to assure a perfect transfer of the floor motion.

All sensors were linked with electrically shielded cables to a data acquisition system OROS OR 38. The signals of the accelerometers were sampled with $256 \mathrm{~Hz}$ and digitized with a resolution of $24 \mathrm{bit}$.

\subsection{Experimental program}

The experiments carried out on site are summarized in Table 2. At both construction stages 1 and 2, an AVT was performed with the aim to identify the modal parameters at a very low excitation level and to get an overview of the natural frequencies for designing the random excitation signals of the FVT. FVT experiments consisted of three steps. First, tests with broad band random excitation were carried out in order to assess the natural frequencies for higher levels of excitation. This was subsequently done again with narrow band random excitation which allowed for a determination of the natural frequencies with increased precision. Finally the building was subjected to harmonic excitations of different level with frequencies matching the natural ones in order to determine the modal damping ratios for different amplitude.

Table 2 Overview on experiments.

\begin{tabular}{|l|l|l|l|}
\hline Step & Experiment & Aim(s) & Data processing \\
\hline 1 & AVT & $\begin{array}{l}\text { Identification of vibration modes } \\
\text { at very low levels of excitation }\end{array}$ & N4SID \\
\hline $2.1 \quad \begin{array}{l}\text { FVT with hydraulic } \\
\text { exciter } \\
\text { randoad band }\end{array}$ & $\begin{array}{l}\text { Identification of vibration modes } \\
\text { at different levels of excitation }\end{array}$ & N4SID \\
\cline { 2 - 5 } & $\begin{array}{l}2.2 \\
\text { Nandom excitation } \\
\text { randow band }\end{array}$ & $\begin{array}{l}\text { Identification of specific vibration } \\
\text { modes at different levels of } \\
\text { excitation }\end{array}$ & N4SID \\
\hline $\begin{array}{l}\text { Harmonic } \\
\text { excitation with } \\
\text { sudden stop and } \\
\text { subsequent free } \\
\text { vibration }\end{array}$ & $\begin{array}{l}\text { Identification of specific vibration } \\
\text { modes at different levels of } \\
\text { excitation }\end{array}$ & ERA \\
\hline
\end{tabular}


The hydraulic actuator was operated in displacement controlled mode. The command displacement was computed based on the desired acceleration of the shaking mass by double-time integration. The proportional-integral-derivative (PID)-controller parameters of the displacement control loop were adjusted iteratively to ensure that the actual acceleration of the shaking mass corresponded to the desired acceleration. Fig. 9 exemplary shows the empirical probability density function and the square root of the power spectrum density of a broad band random excitation.

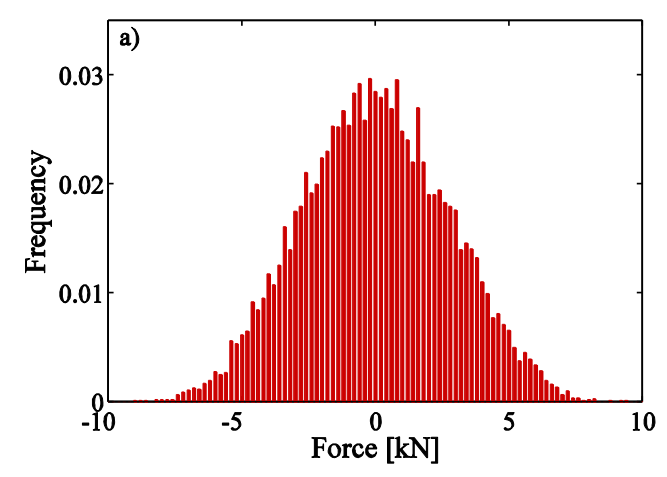

(a)

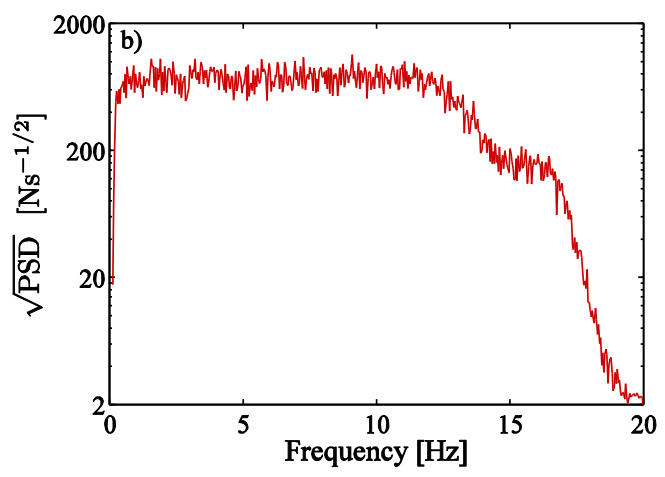

(b)

Fig. 9 Empirical probability density function (a) and square root of the power spectrum density of a broad band random excitation (b).

\subsubsection{Data processing}

The data from AVT and FVT were analysed with the algorithm N4SID (Overschee and De Moor 1996) by identifying the system matrices of the linear, time invariant system

$$
\begin{aligned}
\frac{d x(t)}{d t} & =A x(t)+B u(t)+K e(t) \\
y(t) & =C x(t)+D u(t)+e(t) \\
x_{0} & =x\left(t_{0}\right)
\end{aligned}
$$

$A, B, C, D$ und $K$ are the system matrices, $x(t)$ is the state vector, $y(t)$ the output vector, $u(t)$ the input vector und $e(t)$ the vector of the errors. The computation was performed with the algorithm implemented in Matlab®.

Once the linear system had been identified, natural frequencies and modal damping were computed from the eigenvalues $\lambda_{i}$ of the system matrix $A$ by 


$$
\begin{aligned}
f_{i} & =\sqrt{\operatorname{Re}\left(\lambda_{i}\right)^{2}+\operatorname{Im}\left(\lambda_{i}\right)^{2}} \\
\zeta_{i} & =\frac{\operatorname{Re}\left(\lambda_{i}\right)}{f_{i}}
\end{aligned}
$$

Mode shapes were computed by first transforming the system matrix $C$ with the matrix of eigenvectors $T$ of the system matrix $A$. The mode shape associated to the natural frequency $\lambda_{i}$ corresponds to the i-th column of the transformed system matrix $\hat{C}=C T$. The imaginary part of the complex mode shape was minimized by a multiplication with a suitable complex number of modulus one. This scaling does not have any effect on natural frequencies and modal damping ratios.

The data analysis of the free vibration tests was performed with the Eigensystem Realization Algorithm (ERA) (Juang and Pappa 1985) using only the free vibration part of the data. The algorithm was used to estimate the system matrices $A$ and $C$ as well as the initial value of the state vector $x_{0}$ of the linear, time invariant linear system

$$
\begin{aligned}
\frac{d x(t)}{d t} & =A x(t) \\
y(t) & =C x(t)+e(t) \\
x_{0} & =x\left(t_{0}\right)
\end{aligned}
$$

The ERA algorithm was implemented in Matlab®.The modal parameters were computed as described in the previous paragraph.

\section{$4 \quad$ Results}

\subsection{Vibration modes}

\subsubsection{Forced vibration tests (FVT)}

The largest singular values of the cross correlation matrix in frequency domain provide a good overview about the excited vibration modes. The cross-correlation matrix was calculated with the data from an experiment with broad band random excitation at construction stage 1. Fig. 10a displays the three largest singular values for a test with excitation in transverse direction. The two characteristic peaks of the largest singular value at approximately $3.9(\mathrm{~m} 1)$ and $4.9 \mathrm{~Hz}(\mathrm{~m} 2)$ reveals the existence of two vibration modes. A third natural frequency with a significantly weaker impact on the greatest singular value than the other two can 
be identified at a frequency of approximately $6.8 \mathrm{~Hz}(\mathrm{~m} 3)$. The peak in the spectrum of the $2^{\text {nd }}$ singular value confirms the existence of the third vibration mode.

The well distinguishable peak at about $6.8 \mathrm{~Hz}$ in largest singular value of the test with excitation in longitudinal direction reveals the existence of a third vibration mode (Fig. 10b). The second peak at about $4.9 \mathrm{~Hz}$ coincides with the one identified in the test with excitation in transverse direction. The vibration mode with the smallest natural frequency cannot be identified in the spectrum of the largest singular value. However, it emerges clearly in the spectrum of the second singular value.
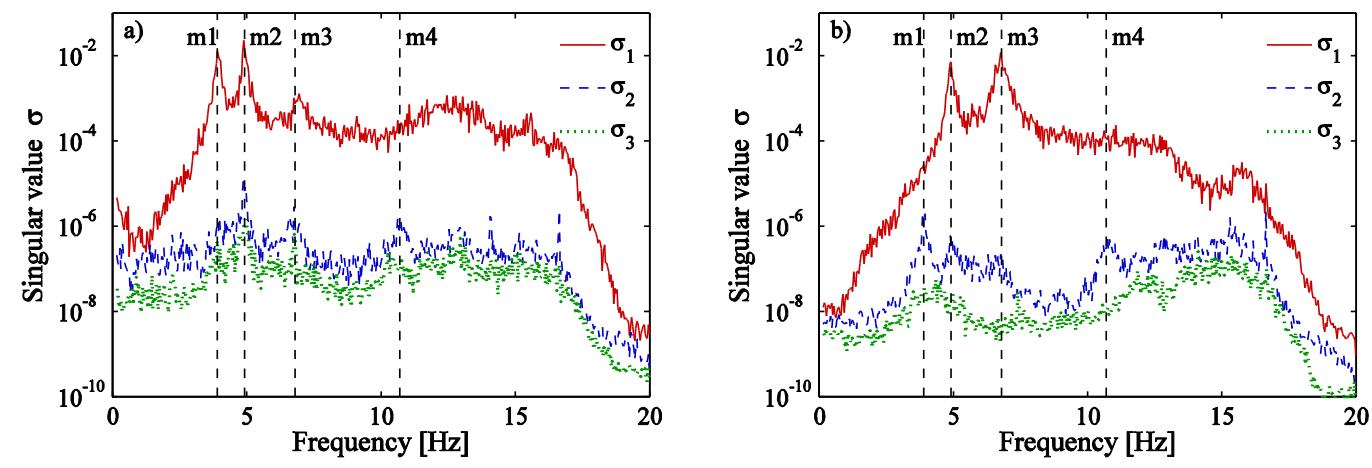

Fig. 10 Singular values of the cross correlation matrix of tests with transversal (a) and longitudinal (b) broad band random excitation.

The greatest singular value does not provide any further hint for the existence of additional vibration modes. Analysing the shapes of the second greatest singular value, however, reveals a common peak at $10.7 \mathrm{~Hz}(\mathrm{~m} 4)$. Since the signal is very weak it is not sure if $\mathrm{m} 4$ is really a vibration mode.

The plots of the singular values show (Fig. 11 - Fig. 14) that the vibration mode $\mathrm{m} 1$ is mainly a transversal oscillation while the vibration mode $\mathrm{m} 3$ is mainly an oscillation in longitudinal direction. The vibration mode $\mathrm{m} 2$, which is identifiable from the largest singular values of both tests, exhibits a motion in both directions and might therefore be associated to a torsional mode. The signal of the mode $\mathrm{m} 4$ is too weak to allow a reliable estimation of its motion. Since the associated peak occurs in both plots the mode seems to exhibit a motion in both directions. 
This result matches well with results obtained with the N4SID algorithm. The first vibration mode $\mathrm{m} 1$ oscillated essentially in transversal direction. Fig. 11 displays the motion of the three floors in the horizontal plane and the decomposition of the motion in transversal (red), longitudinal (blue) and rotational (green) motion. The decompositions have been computed using the mode shape of each floor assuming that the horizontal motion of a floor is governed by a rigid body. The motion of a rigid body can be described by a translation in $\mathrm{x}$-direction, a translation in $\mathrm{y}$ direction and a rotation with respect to a centre of rotation. These motion parameters can be related to the displacements at the 4 sensor positions by 8 nonlinear equations by purely geometrical relations. The motion parameters were finally determined with the nonlinear optimization algorithm lsqnonlin implemented in Matlab®.

The second vibration mode $\mathrm{m} 2$ (Fig. 12) has a strong rotational motion with a smaller but still marked component in longitudinal direction and a negligible motion in transversal direction. The third vibration mode m3 (Fig. 13) has a strong motion in longitudinal direction combined with a small rotational component. Also for this vibration mode the transversal direction is negligible. The fourth vibration mode $\mathrm{m} 4$ (Fig. 14) is the second transversal mode with negligible longitudinal and a small rotational motion of the third floor. The very small modal amplitude of the mode shape at the second floor explains why the output signal was so weak. Since the second floor is very close to the nodal point of the mode shape the effectiveness of the excitation was poor.

first floor

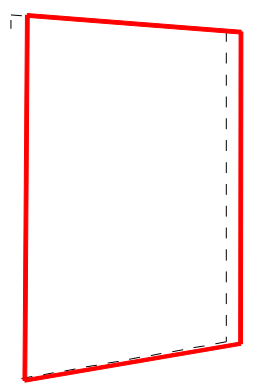

second floor

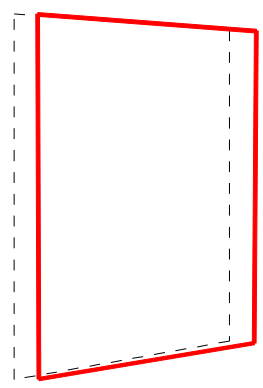

third floor

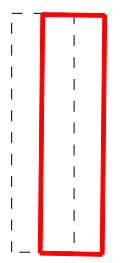

modal amplitude

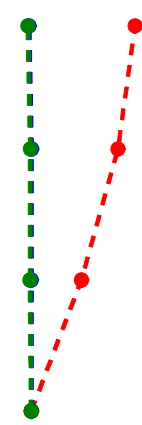

Fig. 11 Mode shape of the first vibration mode (m1) essentially consisting of an oscillation in 
transversal direction (red graph in the modal amplitude picture) and lacking of any longitudinal or rotational movement (blue and green graphs respectively).

first floor

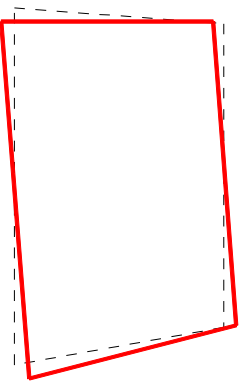

second floor

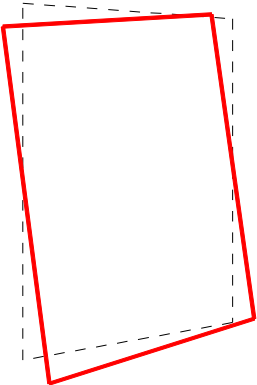

third floor

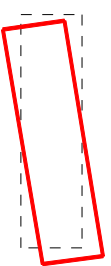

modal amplitude

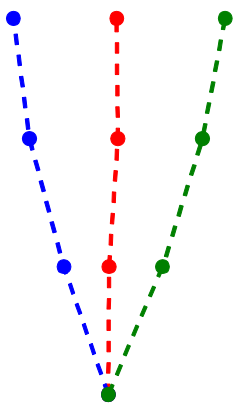

Fig. 12 Mode shape of the second vibration mode (m2) with a strong rotational motion (green), a smaller but still marked component in longitudinal direction (blue) and a negligible motion in transversal direction (red).

first floor

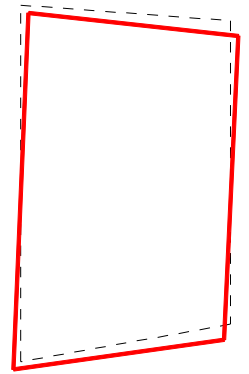

second floor

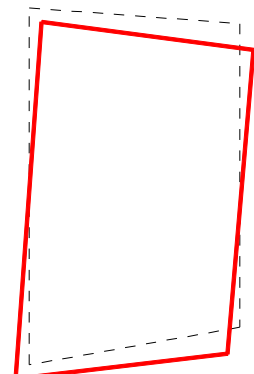

third floor

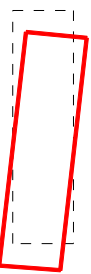

modal amplitude

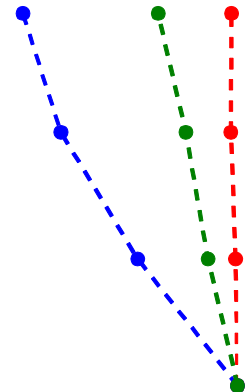

Fig. 13 Mode shape of the third vibration mode (m3) consisting of a strong motion in longitudinal direction (blue) combined with a small rotational component (green).

first floor

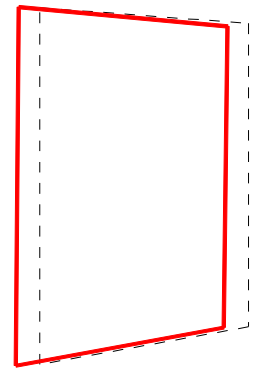

second floor

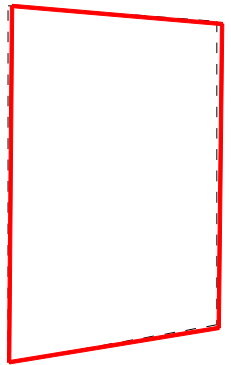

third floor

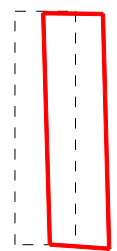

modal amplitude

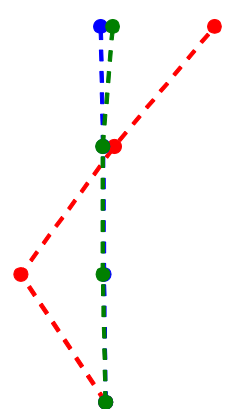

Fig. 14 Mode shape of the fourth vibration mode (m4), which is again a transversal mode (red) with negligible longitudinal (blue) motion and small rotational motion of the third floor (green). 


\subsubsection{Ambient vibration tests (AVT)}

Although the excitation level is much smaller, the singular values of the cross correlation matrix of ambient excitation tests disclose the same vibration modes of forced vibration tests (Fig. 15). The vibration mode $\mathrm{m} 4$ appears much clearer in the spectrum of the greatest singular value since the excitation is not limited to the second floor as in the FVT.

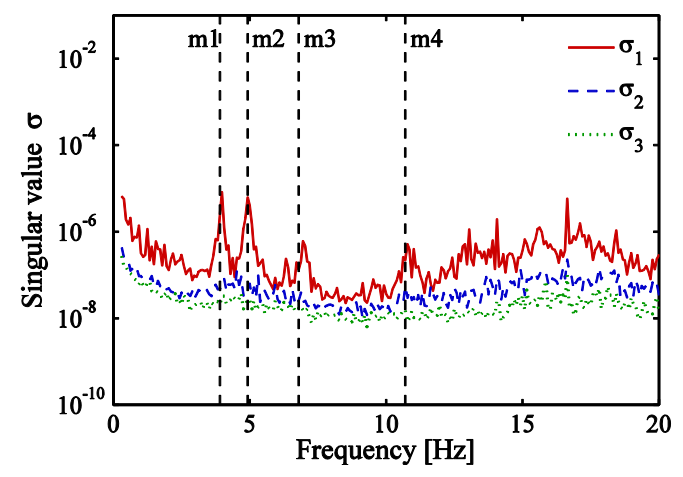

Fig. 15 Singular values of the cross correlation matrix of a test with ambient excitation

The diagonal elements of the correlation matrix, which was computed with the mode shapes $\Psi_{f}$ and $\Psi_{a}$ of the FVT and AVT, respectively, are very close to unity and suggest that the mode shapes essentially coincide.

$$
\text { corr }=\left[\begin{array}{rrrr}
0.9967 & 0.2118 & 0.6579 & 0.5217 \\
0.2262 & 0.9995 & -0.4626 & 0.1581 \\
0.6377 & -0.4128 & 0.9921 & 0.0703 \\
0.4814 & 0.0276 & 0.1246 & 0.9878
\end{array}\right]
$$

The smallest correlation coefficient is associated to the fourth vibration mode m4. Fig. 16 displays the two mode shapes and confirms that they are qualitatively identical and that the quantitative difference is very small. 

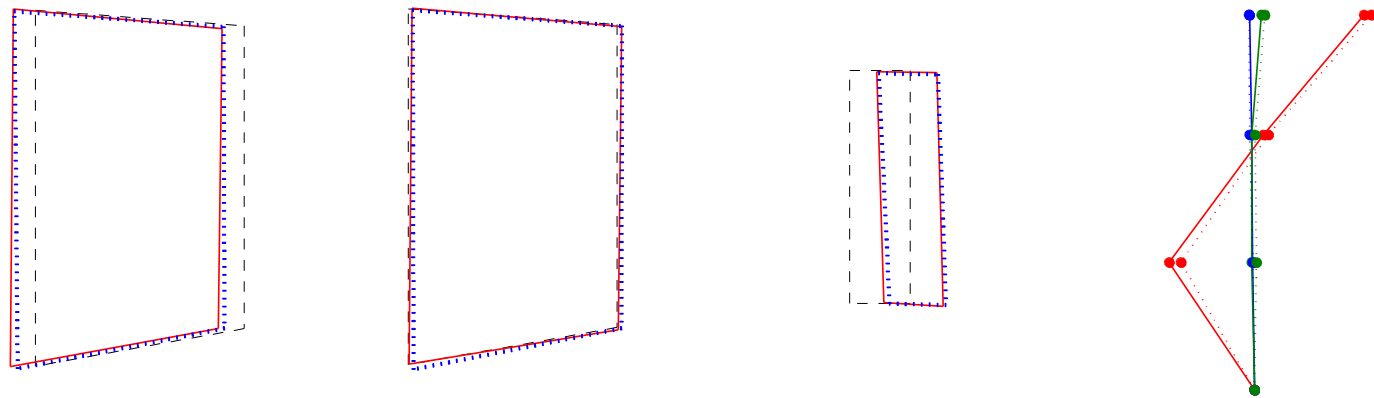

Fig. 16 Mode shape of the fourth vibration mode (m4) identified with data from forced (solid line) and ambient (dotted line) vibration test. Dots (representing storeys) and lines in red colour in the modal amplitude graph dipict a transversal motion of the building. Longitudinal and rotational motions are marked with blue and green dots and lines respectively.

In general, the mode shapes obtained from the FVT have a smaller imaginary part than those computed using the AVT. Table 3 shows the ratio of the vector Euclidian norms of the imaginary to the real part of the mode shape. All complex mode shapes were normalized to unity. The smallest imaginary part with a ratio smaller than $2 \%$ have the mode shapes of the modes $\mathrm{m} 1, \mathrm{~m} 2$ and $\mathrm{m} 3$ that were obtained from FVT. A significantly greater imaginary part is observed for the mode m4 which could not be properly excited with the exciter. Because of the poor excitation it is not fully clear if the imaginary part of the mode shape has a physical background or if it is an artefact of the test method. A possible cause of complex mode shapes is soil structure-interaction because it introduces nonproportional damping. The small imaginary parts of modes $\mathrm{m} 1, \mathrm{~m} 2$ and $\mathrm{m} 3$ suggest that soil structure-interaction was very weak. This outcome is compatible with the rigid and heavy basement of the building that could not be sufficiently excited by the shaker to produce a measurable soil-structure interaction. The imaginary part of mode $\mathrm{m} 4$ might therefore be an artefact originated by the poor excitation because there is no physical reason why mode $\mathrm{m} 4$ should experience soil structure-interaction while all other modes do not.

Mode shapes from AVT have generally greater imaginary parts than mode shapes from FVT. The imaginary part of the mode $\mathrm{m} 4$ is very large although the real part is nearly identical to the mode shape of FVT (Fig. 16). The comparison with the 
results of FVT suggests that the greater imaginary parts of AVT are due to the testing method and have no physical background.

Table 3 Ratio of the vector Euclidian norms of the imaginary to the real part of the mode shape in percent

\begin{tabular}{|l|c|c|c|c|}
\hline Experiments & Mode $\mathbf{m 1}$ & Mode $\mathbf{~ m 2}$ & Mode $\mathbf{~ m 3}$ & Mode $\mathbf{m 4}$ \\
\hline FVT & 1.7 & 1.3 & 1.6 & 8.4 \\
\hline AVT & 6.5 & 2.8 & 4.6 & 23.9 \\
\hline
\end{tabular}

\subsection{Influence of construction stage and vibration amplitude on modal parameters}

The influence of the construction stage and vibration amplitude on modal parameters were investigated using the three vibration modes $\mathrm{m} 1, \mathrm{~m} 2$ and $\mathrm{m} 3$ since they were the only ones which could be identified unambiguously through all construction stages. The vibration mode $\mathrm{m} 4$ was discarded because of its poor reactivity to the excitation.

Fig. 17 displays the results. The displacement amplitude of the third floor was chosen as an index for vibration amplitude. Displacements were computed by numerical integration of the recorded accelerations. The accelerations and all intermediate results were filtered with a high pass Chebishev Type II filter of order 6 having an edge frequency of $2 \mathrm{~Hz}$. Integration is essentially a filtering process with a filter $1 / f$ that amplifies the low frequency components and mitigates the high frequency components. Since at low frequencies accelerometers have a bad signal to noise ratio, integration without high-pass filtering produce a significant corruption of the result which is manifested by drift. This drift can be removed by filtering the low frequency components. Such filtering does not introduce a significant bias if the recorded acceleration signal is dominated by vibrations of structural modes with low damping. The investigated building has this characteristic and Fig. 10 e.g. shows that the frequency components smaller than $2 \mathrm{~Hz}$ are order of magnitude smaller and can therefore be neglected.

In the test with ambient and random excitation the displacement amplitude in Fig. 17 corresponds to the RMS of the vibration displacement during the test period. In the harmonic excitation tests the displacement amplitude refers to $50 \%$ of the 
RMS of the vibration displacement at stationary condition just before interrupting the excitation. Weighting by $50 \%$ considers the fact that the modal parameters were estimated using the free vibration starting from peak vibration amplitude and ending with very small amplitudes. Because of the characteristics of the mode shapes for the vibration modes $\mathrm{m} 1$ and $\mathrm{m} 2$ the RMS was computed considering only the displacements in transversal direction whereas for the vibration mode $\mathrm{m} 3$ only the displacements in longitudinal direction were considered.

The results displayed in Fig. 17 demonstrate a significant influence of vibration amplitude at both construction stages. All natural frequencies decrease with increasing amplitude. For the modes $\mathrm{m} 1$ and $\mathrm{m} 2$ the gradient of the decrease seems to be small at displacements smaller than approximately $0.01 \mathrm{~mm}$. For displacements exceeding this value the gradient is significantly steeper. Furthermore, at construction stage 2 the gradients are generally steeper than at construction stage 1 . In contrast mode $\mathrm{m} 3$ exhibits a more uniform decrease of the natural frequency with vibration amplitude. The natural frequencies of the construction stage 1 are always smaller than the natural frequencies of stage 2 . Because of the greater gradient of decrease at stage 2 the differences between the natural frequencies of the two stages of the modes $\mathrm{m} 1$ and $\mathrm{m} 2$ become smaller with increasing vibration amplitude.

Generally modal damping ratios increase with displacement amplitude. For all modes the damping increase by roughly $100 \%$ with respect to the values obtained with AVT. At construction stage 2 the damping ratios of the modes $\mathrm{m} 1$ and $\mathrm{m} 2$ are greater than at construction stage 1 . For mode $\mathrm{m} 3$ a gap between the damping ratios of the two construction stages is identifiable only at the AVT.

The results obtained with the free vibration tests do not always match well with the results obtained with random excitation. This outcome may be a result of the definition of the displacement amplitude. 

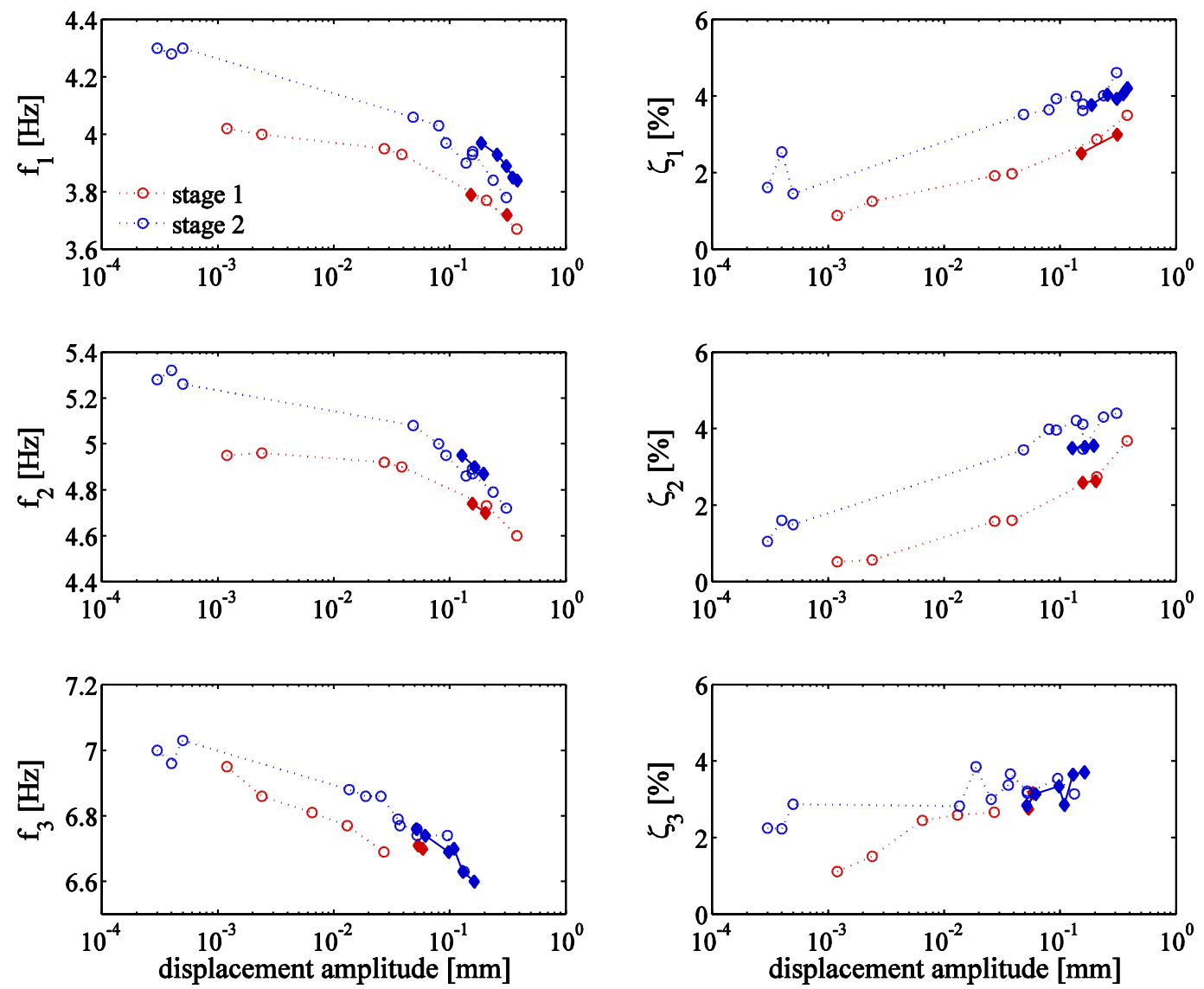

Fig. 17 Changes of natural frequencies and modal damping ratios

Despite the significant changes observed on natural frequencies and modal damping ratios the mode shapes are only weakly influenced by the construction stages. Fig. 18 to Fig. 20 show that the changes of the mode shapes are marginal. The most significant changes occurred at the vibration mode 2 . The correlations are very high:

$$
\operatorname{corr}=\left[\begin{array}{ccc}
0.9969 & 0.1913 & 0.7013 \\
0.2583 & 0.9984 & -0.3547 \\
0.6401 & -0.4533 & 0.9962
\end{array}\right]
$$



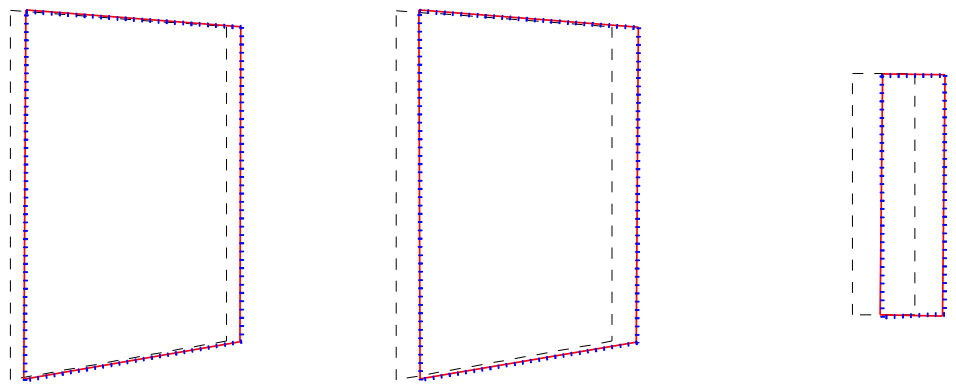

Fig. 18 Mode shapes of the first vibration mode of stages 1 and 2. Dots (representing storeys) and lines in red colour in the modal amplitude graph depict a transversal motion of the building. Longitudinal and rotational motions are marked with blue and green dots and lines respectively.

first floor

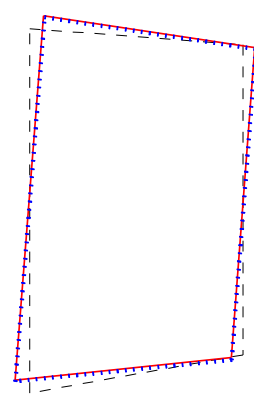

second floor

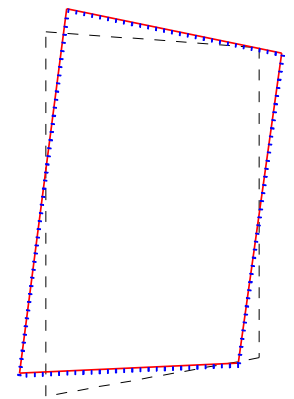

third floor

modal amplitude

Fig. 19 Mode shapes of the second vibration mode of stages 1 and 2. Dots (representing storeys) and lines in red colour in the modal amplitude graph depict a transversal motion of the building. Longitudinal and rotational motions are marked with blue and green dots and lines respectively.

first floor

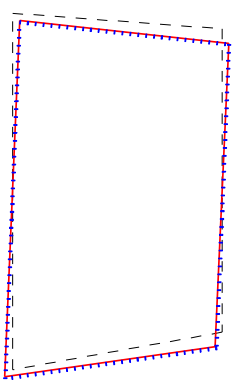

second floor

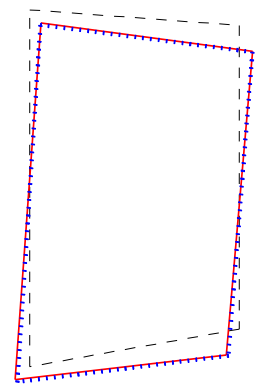

third floor

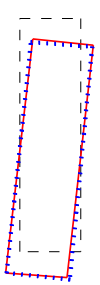

modal amplitude

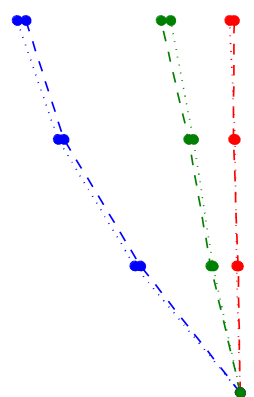

Fig. 20 Mode shapes of the third vibration mode of stages 1 and 2. Dots (representing storeys) and lines in red colour in the modal amplitude graph depict a transversal motion of the building.

Longitudinal and rotational motions are marked with blue and green dots and lines respectively. 


\section{Discussion}

\subsection{Impact of vibration amplitude}

The test results show that natural frequencies significantly decrease with increasing vibration amplitude. In the investigated amplitude range the decrease was ranging from $5 \%$ to $10 \%$. This decrease corresponds to an overall stiffness reduction by $10 \%$ to $20 \%$, which is a quite important figure considering the modest amplitude ranges that could be achieved with the tests. Since the gradient of the decrease tends to increase with increasing vibration amplitude the results suggest that for vibration amplitudes exceeding those of the tests a further stiffness reduction is likely to occur.

As expected, the natural frequencies provided by AVT represent an upper bound. Because of the extremely small amplitude involved, the most straightforward interpretation is that static friction between construction components increases the overall stiffness of the building. Within this interpretation scheme, the increase of the gradient of natural frequencies with increasing vibration amplitudes can be associated to an incremental conversion of static to sliding friction. Such a mechanism would explain the significant growth of modal damping with increasing amplitudes and the observations that natural frequencies at low vibration amplitudes were reproducible after having performed tests with higher vibration amplitudes.

\subsection{Ambient vibration tests}

The results demonstrate that natural frequencies and modal damping ratios computed using data from AVT requires a suitable interpretation in order to provide reliable information about the structure. At ambient vibration amplitudes, non-structural components provided a stiffness increase by $10 \%$ to $20 \%$. Since this additional stiffness is successively nearly completely lost with increasing amplitudes it is important to avoid associating the full stiffness obtained from measured natural frequencies to structural walls otherwise the stiffness of structural walls would be overestimated. Unfortunately, in practice, a reliable estimation of the impact of non-structural components to the observed natural 
frequencies of a specific building is probably difficult to achieve. All published dynamic tests on timber buildings report a reduction of natural frequencies at testing amplitudes greater than ambient vibration amplitudes. The reduction, however, differs significantly from building to building because of the different designs and type of non-structural components.

In our test, modal damping ratios computed using ambient vibration data are generally smaller than modal damping ratios obtained from FVT. They fit quite smoothly into the damping ratios obtained with FVT tests. This result suggests that modal damping ratios might be significantly underestimated if results from AVT are used. The additional damping due to non-structural components seem to be less critical concerning possible misinterpretations since it does not diminish with increasing vibration amplitude. Nevertheless, based on our experience, modal damping ratios extracted with AVT data can deviate rather substantially from damping ratios obtained with FVT, as was also pointed out by Hafeez et al. (Hafeez et al. 2014). It is therefore always recommended to check their reliability, if possible, with independent tests.

\subsection{Impact of non-structural building components}

Including the non-structural building components in stage 2 had the effect of increasing the natural frequencies and therefore the overall stiffness of the building. Since the gradient of natural frequency changes in construction stage 2 is greater than in construction stage 1 these non-structural components seem to show a more rapid stiffness loss with increasing amplitudes than the load-bearing structural walls. This greater stiffness loss tends to close the gap between the natural frequencies of the first and second construction stage such that at greater vibration displacements the natural frequencies eventually converge. Such a convergence would imply a nearly complete stiffness loss of the non-structural components. According to the observed changes of natural frequencies of the vibration modes $\mathrm{m} 1$ and $\mathrm{m} 2$ displayed in Fig. 17 such a convergence may occur already at vibration displacements of the third floor of about $1 \mathrm{~mm}$. This result implies that the contribution of non-structural components to overall stiffness is becoming negligible at an inter-storey drift of less than $1 \mathrm{~mm}$. Since this 
convergence occurred without producing any visible damage of the structural and non-structural components, the consequence is that the stiffness of the nonstructural components was fully mobilized only at very small vibration amplitudes. With increasing amplitudes the non-structural components were successively decoupled. Compared to the first natural frequency in transversal direction estimated by the designer $\left(f_{1, y} \approx 1 \mathrm{~Hz}\right)$ the natural frequency of vibration mode $\mathrm{m} 1$ measured in construction stage 2 was considerably higher ( $f_{1, y} \approx 4 \mathrm{~Hz}$ for amplitudes of $10^{-4} \mathrm{~mm}$ and $f_{1, y} \approx 3.7 \mathrm{~Hz}$ for amplitudes of $0.4 \mathrm{~mm}$ ). Consequently there is in fact a marked contribution to the overall stiffness of the building by non-structural walls and walls with openings not accounted for in the designer's model. A range of natural frequency between 3.7 and $4 \mathrm{~Hz}$ corresponds to fundamental periods of 0.25 to $0.27 \mathrm{~s}$ which would require basing the seismic design of the building on the plateau value of the design spectrum (Fig. 3).

Apparently the non-structural components have the effect to increase modal damping ratios. Contrary to natural frequencies, in the investigated amplitude range, this increase is approximately independent of vibration amplitudes. If this trend would persist also at greater vibration displacements when the non-structural components would have lost most of their stiffening effect is, unfortunately, unknown. Shake table tests (Filiatrault et al. 2008; Filiatrault et al. 2010) suggest that damping does not diminish with increasing vibration amplitudes. Considering only the damping of structural components would therefore be probably conservative.

\subsection{Mode shapes}

The mode shapes change only very marginally when introducing non-structural components and when increasing the vibration amplitudes. The observed low sensitivity of mode shapes to structural changes is in line with the results of Sartori et al. (Sartori et al. 2012). In addition, the result that mode shapes computed using ambient vibration data turned out to be reliable is in agreement with the finding of Hafeez et al. (Hafeez et al. 2014). These results suggest that mode shapes are largely dominated by structural walls. The distributed location of 
the non-structural components and the low sensitivity of mode shapes to moderate stiffness changes are likely to be responsible for these outcomes.

\subsection{Comparison of vibration modes}

Mode m3, which has a strong motion in longitudinal direction, behaves differently from modes $\mathrm{m} 1$ and $\mathrm{m} 2$. The gap between the natural frequencies at construction stages 1 and 2 at the smallest vibration amplitudes is much smaller compared to modes $\mathrm{m} 1$ and $\mathrm{m} 2$. The closing of the gap with increasing vibration amplitudes is less evident than for the modes $\mathrm{m} 1$ and $\mathrm{m} 2$. Also the difference of damping ratios between the two construction stages are less pronounced in mode m3. An evident gap exists only at very small vibration amplitudes. The noise that was produced during the tests by the concrete kernel prevented in particular at construction stage 1 tests with greater vibration amplitudes because of concerns regarding a possible damage of the building. The differences between modes $\mathrm{m} 1 / \mathrm{m} 2$ and mode $\mathrm{m} 3$ in terms of closing the gap in natural frequencies with increasing amplitude may be attributed to the fact that the additionally installed nonstructural walls in stage 2 were mainly oriented in the longitudinal direction of the building. Since mode $\mathrm{m} 3$ has a dominant motion in longitudinal direction (Fig. 13) the intrinsic in-plane stiffness of these walls prevented a closing of the gap in natural frequencies between stage 1 and 2. Contrary, the modes $\mathrm{m} 1$ and $\mathrm{m} 2$ acts primarily perpendicular to these non-structural walls thus mobilising their much weaker out-of-plane stiffness which had a negligible effect on natural frequencies.

\section{Conclusions}

The tests demonstrated that non-structural components have a significant effect on natural frequencies and consequently on the overall stiffness of timber building. This added stiffness is nearly completely lost already at small vibration amplitudes without producing any visible damage and is completely recoverable. Static friction between building components is the most likely mechanism explaining qualitatively such behaviour. The observed increasing damping with increasing vibration amplitudes is also compatible with an incremental conversion of static to sliding friction. Since the vibration amplitudes achieved during the tests were abundantly below the amplitudes that are expected during an earthquake, little can be said about natural frequencies and modal damping ratios 
at such vibration amplitudes. Shaking table tests showed that an additional significant decrease of stiffness will occur when non-structural components are subjected to damage. It is unknown if this stiffness loss will be able to bridge the huge gap between natural frequencies of the real building and the design model. Therefore underestimating the horizontal stiffness of LFTB in a force based design could be on the unsafe side.

In most of the harmonic loading tests in transversal direction of construction stage 2 the acceleration at the second floor exceeded $0.25 \mathrm{~ms}^{-2}$ with peaks reaching $0.6 \mathrm{~ms}^{-2}$. Such peak accelerations are abundantly exceeding the vibration serviceability limit of approximately $0.1 \mathrm{~ms}^{-2}$ that is recommended by ISO 10137 (ISO 2009) for residential buildings subjected to wind loads with a return period of one year. Therefore for vibration amplitudes in the range of vibration serviceability limits the non-structural components may contribute to a global stiffening of the building. Since the spectrum of wind loads in the frequency range of about several Hertz generally increase with decreasing frequencies, neglecting the stiffening effect of non-structural components overestimates the vibration amplitudes.

\section{Acknowledgments}

This study was supported by the Swiss Federal Office for the Environment FOEN (Fonds zur Förderung der Wald- und Holzforschung, Project number 2012.04) and by the Swiss National Science Foundation SNSF (National Research Program 66 "Resource Wood”, project 406640136900).

For having given allowance to perform the experiments as well as for having actively supported preparation and carrying out of the experiments on site the authors express their gratitude to the owner of the building, Ferrario Bau AG, Oberglatt and to the involved designers and manufacturer of the building Zindel Brönnimann Ferrario ZBF Architekten AG, Zurich, Pirmin Jung Ingenieure für Holzbau AG, Rain and Artho Holz- \& Elementbau AG, St. Gallenkappel.

The assistance of the Empa technicians Heinrich Lippuner, Bruno Maag, Slavko Tudor, Milos Dimic, Werner Studer, Robert Widmann and Robert Jockwer taking care of installing the exciter and measuring equipment on site is gratefully acknowledged. 


\section{References}

Akers LE (1966) Particle board and hardboard. Pergamon Press, Oxford

Brunner R, Jung P, Steiger R, Wenk T (2010) Erdbebengerechte mehrgeschossige Holzbauten. Technische Dokumentation der Lignum. Lignum - Holzwirtschaft Schweiz, Zürich

CEN (2001) EN 12369-1: Wood-based panels - Characteristic values for structural design - Part 1: OSB, particleboards and fibreboards. European Committee for Standardization, Brussels, Belgium.

CEN (2004a) EN 622-2: Fibreboards - Specifications - Part 2: Requirements for hardboards. European Committee for Standardization, Brussels, Belgium.

CEN (2004b) EN 1991-1-4: Eurocode 1 - Actions on structures - Part 1-4: General actions - Wind actions. European Committee for Standardization, Brussels, Belgium.

CEN (2004c) EN 1998-1: Design of structures for earthquake resistance - Part 1: General rules, seismic actions and rules for buildings. European Committee for Standardization, Bruxelles, Belgium.

CEN (2004d) EN 13986: Wood-based panels for use in construction - Characteristics, evaluation of conformity and marking. European Committee for Standardization, Brussels, Belgium.

CEN (2006) EN 300: Oriented Strand Boards (OSB) - Definitions, classification and specifications. European Committee for Standardization, Brussels, Belgium.

CEN (2009a) EN 338: Structural timber - Strength classes. European Committee for Standardization, Brussels, Belgium.

CEN (2009b) EN 520: Gypsum plasterboards - Definitions, requirements and test methods. European Committee for Standardization, Brussels, Belgium.

CEN (2009c) EN 15283-2: Gypsum boards with fibrous reinforcement - Definitions, requirements and test methods - Part 2: Gypsum fibre boards. European Committee for Standardization, Brussels, Belgium.

Ellis BR, Bougard AJ (2001) Dynamic testing and stiffness evaluation of a six-storey timber framed building during construction Engineering Structures 23:1232-1242. doi:10.1016/S0141-0296(01)00033-5

Filiatrault A, Christovasilis I, Wanitkorkul A (2008) Experimental seismic investigation of a full-scale woodframe building. Paper presented at the Structures Congress 2008: Crossing Borders, Vancouver, British Columbia, Canada, April 24-26, 2008

Filiatrault A, Christovasilis IP, Wanitkorkul A, van de Lindt JW (2010) Experimental Seismic Response of a Full-Scale Light-Frame Wood Building J Struct Eng-Asce 136:246-254. doi:10.1061/(Asce)St.1943-541x.0000112

Hafeez G, Mustafa A, Doudak G, McClure G (2014) Predicting the Fundamental Period of Light-Frame Wood Buildings Journal of Performance of Constructed Facilities 28:A4014004. doi:10.1061/(ASCE)CF.1943-5509.0000519

ISO (2009) ISO 10137: Bases for design of structures - Serviceability of buildings and walkways against vibrations. International Organization for Standardization, Geneva, Switzerland.

Juang JN, Pappa RS (1985) An Eigensystem Realization-Algorithm for Modal ParameterIdentification and Model-Reduction J Guid Control Dynam 8:620-627.

doi:10.2514/3.20031 
Kharrazi MHK, Ventura CE, Prion HGL, Taylor GW, Lord JF, Turek M Experimental evaluation of seismic response of woodframe residential construction. In: 4th Structural Speciality Conference of the Canadian Society for Civil Engineering, 2002. pp 1-9

Kohara K, Miyazawa K Full-scale shaking table test of two-story dwelling houses. In: 5th World Conference on Timber Engineering WCTE, Lausanne-Montreux, Switzerland, 1998. pp 548-555

Kolb J, LIGNUM Holzwirtschaft Schweiz, Deutsche Gesellschaft für Holzforschung (2008) Systems in timber engineering loadbearing structures and component layers. Birkhäuser, Basel

Ohashi Y, Sakamoto I, Kimura M (1998) Shaking table tests of a real-scale wooden house subjected to Kobe earthquake. Paper presented at the 5th World Conference on Timber Engineering WCTE, Lausanne-Montreux, Switzerland, August 17-20

Overschee Pv, De Moor BLR (1996) Subspace identification for linear systems theory, implementation, applications. Kluwer Academic Publishers, Boston [etc.]

Ponzo FC, Smith T, Di Cesare A, Pampanin S, Carradine D, Nigro D (2012) Shaking table test of a multistorey post-tensioned glulam building: design and construction. Paper presented at the 12th World Conference on Timber Engineering WCTE, Auckland, New Zealand, July 16-19, 2012

Rainieri C, Fabbrocino G, Cosenza E (2010) Some remarks on experimental estimation of damping for seismic design of civil constructions Shock Vib 17:383-395. doi:10.3233/Sav-2010-0534

Sartori T, Casagrande D, Tomasi R, Piazza M (2012) Shake table test on 3-storey lightframe timber buildings. Paper presented at the 12th World Conference on Timber Engineering WCTE, Auckland, New Zealand, 16-19 July

Sato T, Koshihara M, Kohara K, Miyazawa K, Ohashi Y, Sakamoto I (2000) Shaking table tests and seismic design method of wooden houses with eccentricity. Paper presented at the 6th World Conference on Timber Engineering WCTE, Whistler, BC, Canada, July 31-August 3, 2000

Schweizerischer Ingenieur- und Architektenverein sia (2003) SIA-Norm 265: Holzbau.

SIA (2003a) SIA Standard 260: Basis of structural design. Swiss Society of Engineers and Architects, Zurich, Switzerland, Zürich, Schweiz.

SIA (2003b) SIA Standard 261: Actions on structures. Swiss Society of Engineers and Architects, Zurich, Switzerland, Zürich, Schweiz.

SIA (2003c) SIA Standard 265: Timber structures. Swiss Society of Engineers and Architects, Zurich, Switzerland, Zürich, Schweiz.

SIA (2009) SIA Standard 265/1: Timber structures - Supplementary Specifications. Swiss Society of Engineers and Architects, Zurich, Switzerland, Zürich, Schweiz.

Smith T, Pampanin S, Di Cesare A, Ponzo FC, Simonetti M, Nigro D, Carradine D (2014) Shaking table testing of a multi-storey post-tensioned timber building Paper presented at the New Zealand Society for Earthquake Engineering Technical Conference 2014, Auckland, New Zealand, March 21 - 23, 2014

van de Lindt J, Pei S, Pryor SE, Shimizu H, Isoda H (2010) Experimental seismic response of a full-scale six-story light-frame wood building Journal of Structural Engineering 136:1262-1272. doi:10.1061/(ASCE)ST.1943-541X.0000222 